University of Wollongong

Research Online

University of Wollongong in Dubai - Papers

University of Wollongong in Dubai

January 2020

\title{
Robust facility location decisions for resilient sustainable supply chain performance in the face of disruptions
}

\author{
Balan Sundarakani \\ University of Wollongong, balan@uow.edu.au
}

Vijay Pereira

pereira@uow.edu.au

Alessio Dr Ishizaka

Follow this and additional works at: https://ro.uow.edu.au/dubaipapers

\section{Recommended Citation}

Sundarakani, Balan; Pereira, Vijay; and Ishizaka, Alessio Dr: Robust facility location decisions for resilient sustainable supply chain performance in the face of disruptions 2020, 1-45.

https://ro.uow.edu.au/dubaipapers/1175

Research Online is the open access institutional repository for the University of Wollongong. For further information contact the UOW Library: research-pubs@uow.edu.au 


\title{
Robust Facility Location Decisions for Resilient Sustainable Supply Chain Performance in the Face of Disruptions
}

\author{
Abstract \\ Purpose \\ Facility location and re-location decisions are critical managerial decisions in modern supply chains. Such decisions are difficult in this \\ environment as managers encounter uncertainty and risks. The study investigates establishing or moving distribution facilities in the global supply \\ chain by considering costs, fulfillment, trade uncertainties, risks under environmental trade-offs and disruptive technologies.
}

\section{Design/methodology/approach}

This paper combines the possibilities and probabilistic scenarios for a supply chain network by proposing the novel Robust Optimisation and Mixed Integer Linear Programming (ROMILP) method developed under the potential uncertainty of demand while considering the costs associated with a four-tier supply chain network. ROMILP has been solved in a realtime logistics environment by applying a case study approach.

\section{Findings}

The solution is obtained using an exact solution approach and provides optimality in all tested market scenarios along the proposed global logistics corridor. A sensitivity analysis examines potential facility location scenarios in a global supply chain context.

\section{Research limitations/implications}

Logistics managers can apply the ROMILP model to test the cost-benefit trade-offs against their facility location and relocation decisions while operating under uncertainty. Future research is proposed to extend the literature by applying data from the OBOR logistics corridor. 


\section{Originality/value}

This study is the first to examine sustainable dimensions along the global logistics corridor and investigate the global container traffic perspective. The study also adds value to the Middle East logistics corridor regarding facility location decisions.

Keywords: Robust Optimisation; Facility Relocation; Global Supply Chain Network; COVID-19 Disruptions; Digital Twin; Disruptive technologies.

Paper type: Research paper

\section{Citation}

Sundarakani, B., Pereira, V. and Ishizaka, A. (2020), "Robust facility location decisions for resilient sustainable supply chain performance in the face of disruptions", The International Journal of Logistics Management, Vol. ahead-of-print No. ahead-of-print. https://doi.org/10.1108/IJLM$\underline{12-2019-0333}$

\section{Introduction}

Globalisation has impacted the size, scale and location of production and storage facilities in supply chain networks in numerous ways. There has been a wave of new assembly and supplier plant locations in countries such as China, India, Thailand, Vietnam, Brazil, Mexico, Turkey and some Eastern European countries due to their cheaper and more accessible raw materials supply, lower labour costs and accessibility to the extended consumer market (Marchet et al. 2017). At the same time, developed economies such as Japan, the UK and the USA have improved their 
logistics infrastructure with much slower rates of market growth compared to that of emerging markets. This wave of location decisions has often created conflicting trade-offs in cost benefit analysis for firms such as apparel, automobile, electronic goods, branded consumer goods and other fashion goods manufacturers. If firms have considered only the 'lower manufacturing cost' as the prime reason for outsourcing and offshoring decisions, then the resulting supply chain structure could have led to a different network configuration and associated firm financial performance. In reality, however, in addition to low manufacturing costs, other new dimensions such as accessibility to the emerging market, growing logistics infrastructure, enhancement in affiliated technologies, improved supply chain networks, a focus on environmental concerns and sustainability in business offerings are considered to be some of the new norms of modern industry location decisions. In earlier research, Simchi-Levi et al. (2004: p79) defined that, "the strategic level firm location decisions in a supply chain network were aimed to have longitudinal effect on the firm performance which were aligned towards tactical decisions such as, location, capacities of warehouses and manufacturing plants and the flow of material through the multimodal logistics network". These conventional objectives leave many questions unanswered, especially considering location decisions are driven by probable and possible situational factors that reinforce such decisions in modern global logistics situations (Sarkis et al. 2020). This motivates researchers to understand and examine these reinstating forces and thus contribute to the theory and practice of the logistics industry as discussed in the remainder of this paper.

\subsection{Research significance}

Recent uncertainty associated with COVID-19 has resulted in supply chains impacting the logistics network profoundly (Ivanov, 2020 and Sarkis et al., 2020). It may challenge the conventional supply chain channel communication and degree of change in boundary conditions and 
remains a mystery due to the fact that there is a need for new e-commerce technologies, which are nascent in their adoption thereof (Triblmaier, 2018). Apart from the most recent COVID-19 challenges, other comparable supply chain risks and uncertainties have similar detrimental effects on logistics networks and thus challenge the traditional assumptions associated with the supply chain and logistics network design and impose decision variables and constraints that are connected to disruptive incidents (Sarkis et al. (2020)).

Logistics aspects such as borderless trade environments, growing infrastructural needs, the surging demand of cost-effective solutions and existing or emerging environmental and regulatory pressures call for manufacturers and logistics service providers to redesign their supply chain network. Therefore, the global supply chain landscape is constantly changing to keep abreast of such emerging constraints and pressures. According to Melo et al. (2009), uncertainty is one of the most challenging problems when managing today's supply chain. However, the literature on uncertainty in location decisions in a supply chain management context reveals little (Jayaraman et al., 2015). Although there are existing supply chain uncertainty and risk studies, the recent COVID-19 outbreak has created an unprecedented and extraordinary situation in the global logistics and supply chain network and therefore the need to progress supply chain resilience research and practices has become both significant and timely (Ivanov and Dolgui, 2020).

In order to respond effectively to any uncertainty, firms often need to proactively design their supply chain management network system by putting in place a well-established logistics structure that reduces the cost of the various supply chain components and improve its performance to meet the realistic constraints of the day. In addition, policy changes by the Chinese government to promote the One Belt and One Road (OBOR) initiative created significant speculation around the existing logistics players to study the feasibility options (Aliev (2016), Aoyama (2016), 
Ploberger (2017) and Rakhmangulov et al. (2018)). Hence, this research aimed to study the feasibility of facility or Distribution Centre (DC) location or re-location in a global supply chain network, which centres around a global logistics corridor across OBOR by adopting a practical and robust approach to handle such external and internal supply chain uncertainties.

The rest of this paper is structured as follows. Section 2 surveys the literature on robust optimisation and facility location. Section 3 introduces the robust optimisation model, compares the proposed model against the existing models and sets the solution approach. Section 4 discusses the case results for the ABC Global Apparel firm and its facility location problem, while Section 5 highlights the research findings and discusses the implications based on the previous section. Finally, Section 6 highlights the theoretical contributions, key managerial contributions and recommendations with regards to the direction of future research.

\section{Literature Review}

\subsection{Facility location decisions}

Many scholars have discussed the multi-dimensional problem of firm re-location decisions in a limited application and geographical context. As early research in this direction, Moses and Williamson (1967) first discussed the firm re-location problem, as in the original location vis-a-vis re-location to alternate locations in a metropolitan environment. Brown and Gibson (1972) then proposed a plant location model, which became a much-considered model by researchers due to its simplicity and viable outcome. The Brown-Gibson model is a quantitative model which was developed to evaluate alternative plant locations using certain objective and subjective factors. However, the model was deemed unsuitable 
for modern facility location decisions due to the limitations of the subjective and objective factors; this is because objective factors include cost, time, energy and distance, whereas subjective factors include policy, governance, trust and cultural aspects (Young et al., 2009).

While exploring certain key anthropological studies on firm location, Wachter (1978) modelled the firm location decisions, wherein the employment aggregate changes due to the birth and death of manufacturing firms. The study also theorised that employment changes in suburban jurisdictions result only from the re-location of city plants (Wachter, 1978). Consequently, traditional location decisions were influenced by the agglomeration of industries, which ignored the total landed cost of goods to the consumer (Feller, 2008). Following from there, Erickson and Wasylenko (1980) developed a model for firm re-location and site selection decisions in suburban municipalities. In an extended study, Cordeau et al. (2006) considered much more than the generic facility location setup by including procurement, production, inventory, distribution and routing decisions. Zhang and Yang (2007), on the other hand, examined the facility location problem in a perishable commodities emergency system under time constraints. Recently, Benyoucef et al. (2013) simultaneously considered a facility location and supplier selection problem with random demand and under reliable and unreliable suppliers and solved the model by using a Lagrangian relaxation approach.

Likewise, Lu et al. (2017) and Kacem et al. (2018) presented a robust stochastic supply chain network model in the context of a case study to highlight the risk preference association and capacitated machine allocation problems. However, Gammelgaard (2019) argued that the emerging technological nature of changing the competitive advantage that a supply chain can attain by shaping its logistics strategies can be highly significant. Therefore, addressing multiple strategic decisions in logistics related problems involves multiple rules and trade-offs, which require 
an integrated and robust approach to achieve better results (Petrović et al. 2018). The following literature section discusses some of these emerging constraints and their nature more comprehensively.

\subsection{Emerging constraints}

Due to the nature of disruptive technologies (Gammelgaard (2019), Liao-Troth (2012)) and changing regulations (Nilsson and Christopher (2018)), the contemporary decision variables are challenged through new objective functions of pricing on carbon emissions, on the cost of risk, on trade friction, on service level improvements and on a sustainable logistics facility apart from the conventional objectives of transportation minimisation, order shipment size reduction and inventory minimisation (Nair et al. (2016), Nair and Reed-Tsochas (2019)). In this context, Srivastava (2007) defined "green supply chain management (GSCM) as the integration of environmental thinking into supply chain management". In GSCM, the environmental impacts of "carbon emissions" from transportation have been considerably attractive for research, as studies have found that almost $35 \%$ of the total transportation greenhouse gas emissions come from trucks as the only viable performed mode of transport in most developing countries (Anciaux et al. 2007). Emissions control is equally effective and significantly important for all stationary and nonstationary formats of a logistics system, as proposed by Sundarakani et al. (2010) and Jayaraman et al. (2015).

To adapt to the challenges faced by the global logistics industry of the new business environment, the aforementioned factors are considered to be risky and thus call for a resilient model and associated solutions. In reality, many situations that impact the business parameters are found to be uncertain, and usually no information about the probabilities are known a priori. Therefore, methodologies such as fuzzy stochastic programming and robust optimisation are applied to deal with the uncertainty (Ben Abdelaziz and Masri, 2005). For example, Yang et al. (2007) 
studied a DC location problem in a fuzzy environment and Hasani et al. (2012) designed a robust closed-loop supply chain for perishable items. However, these studies have several limitations in terms of model assumptions, constraint developments and solvability, as captured in the literature (Feller, 2008, Young et al., 2009 and Lechler et al., 2019).

Earlier, Hassanzadeh-Amin and Zhang (2013) and Masri (2017) developed a multi-objective closed loop facility location model under stochastic demand under supply chain network theory. Likewise, Baghalian et al. (2013) offered a robust supply chain network design with service level against disruptions and demand uncertainty and applied the model to a case study. The risk resilience, trust and carbon emission related constraints and decisions in the proposed model complement and contribute to the theoretical development in the supply chain and logistics network theory proposed by Hearnshaw and Wilson (2013). However, the main theoretical grounding of this research is positioned on the "disruptive innovation theory" in which the innovation is more on supply chain and logistics processes rather than product or service innovation (Christensen et al., 2015). The resilience driven robust decision network model is comprehensively discussed in subsequent sections.

\subsection{Limitations of existing solution approaches}

According to Leung et al. (2007), supply chain uncertainties are associated with unforeseen events and occurrences which exist with both the data and the model; despite this, extant research is limited on the robustness and robust optimal solution front. According to Sengupta (1991), robustness for stochastic programming models means to be "close" to optimal for all input scenarios, and "almost" feasible to all data scenarios. Such an approach is called "Robust Optimisation" (RO), which was first introduced by Mulvey et al. (1995) as a goal programming model. Subsequently, 
both Mulvey and Ruszcczynski (1995) and Bai et al. (1997) defined RO as a type of stochastic non-linear programming model in which a concave risk aversion function is added in the specification of the objectives.

Since then, RO has been used for capacitated and un-capacitated large scale facility location problems. Escudero et al. (1993) presented a RO formulation to handle outsourcing in manufacturing, and Gutierrez and Kouvelis (1995) developed RO models to solve a multinational corporation's production scheduling problems. The RO approach was considered as a dual-response production loading problem and provided significant performance on a two-stage stochastic programme by Wu (2006). Similarly, Castillo (2009) later developed a RO model for large scale system applications which explicitly incorporate the conflicting objectives of solution and model robustness. Additionally, Kanyalkar and Adil (2010) and La Torre (2003) applied RO in a multi-site procurement-production-distribution problem, while Behzadi et al. (2013) applied the RO approach in the food industry to increase safety under uncertainty. It was found in a survey by Snyder (2006) on the literature of facility location problems under uncertainty that the models developed are mainly non-deterministic polynomial hard (NP-hard) models, as discussed by Rahmaniani et al. (2013). In the context of downstream logistics network, in an attempt to solve the probabilistic nature of location decision in travelling sales problem (TSPs) of two echelon supply chain, Bertsimas (1989) considered a polynomial time heuristics method and an euclidean problem approach for generic facility location decisions. However, much of the TSPs are found to be theoretically saturated as depicted by Chan and Bake (2005) and they found to be very much limited to last mile delivery locations which can not be generalised across extended supply chain with multilocation decisions. 
Further, fuzzy stochastic programming or the robust method has been used to model the uncertainty in facility locations for up to three echelons under different demand probability distributions in a further extension for future research (Kahramana et al., 2003; Gülpinar et al., 2013). In that contextual space, De Rosaa et al. (2013) proposed a bi-directional three-echelon facility network performance assessment under supply and demand uncertainty but left many research directions as scope for improvement. Further, a p-median approach was attempted by Snyder and Daskin (2006) when solving manufacturing facility themed location problems but was limited to several angles of analysis. In this direction of research, earlier studies conducted by Atamtürk and Zhang (2006) and Sundarakani and Van Over (2010) laid an initial grounding for dealing with uncertainty aspects in an extended four tier supply chain network robustness, whilst warranting that there were many research gaps to be addressed by future researchers.

Based on these comprehensive reviews, the research pointed out that the assessing firm's location and re-location decisions in a global logistics network to deal with robustness have been associated with many uncertainties and risk factors, which are not addressed by the existing research and therefore this study aimed to address this research gap as appropriate in the proceeding sections.

\subsection{Research gap}

The section underpins the theoretical side and contribution of the proposed model as compared to the other RO models discussed in the literature, as shown in Table 1.

[Place - Table 1. Features of proposed model vs. other RO models - here] 
From Table 1, the facility location and allocation problem was developed by Geoffrion and Graves (1974) considering the transportation and fixed and variable facility location costs in a deterministic 3-tier supply chain. Yu and Li (2000) and Leung et al. (2007) developed a RO model for production planning. Next, Rahmaniani et al. (2013) proposed a robust model for the facility location problem mainly based on the classical Travelling Salesman Problem (TSP) by minimising the transportation and fixed facility costs through heuristics for a two-echelon supply chain. As identified in Table 1, global supply chain networks incorporating various emerging cost components, multimodal transportation constraints, allowable carbon emission aspects and trade friction are not well studied in the literature.

Gulpinar et al. (2013) developed stochastic and robust models for the facility location problem by adding inventory holding costs. The robust approach in Gulpinar et al.'s work is based on the model developed by Ben-Tal and Nemirovski (1998) as a nonlinear function of robust convex, which is solved using simulations. Although Behlazadi (2017) proposed a RO problem that is linear in terms of their production and transportation costs, the problem was focused on a New Zealand agricultural business with limited constraints. Finally, in the proposed model, an exact solution is provided through various cost minimisations under both possibility and probability for a four-echelon sustainable logistics system and thereby proposing robust resilient strategies for firms. The need of such robust resilient strategies is timely and significant due to the COVID19 outbreak impacting the performance of the logistics industry, as captured by Ivanov and Dolgui (2020) in their position paper. Hence, in our research, the RO approach is chosen for a four-echelon dedicated facility location problem in a global supply chain on top of a Mixed Integer Linear Programme, extending the work of the existing literature and adding to that of the "supply chain network theory" based on emerging constraints and decision variables. 
Hence, the paper applies a hybrid approach integrating RO with the MILP model (thus proposed as ROMILP) to handle the objectives and constraints for the facility location and re-location decisions in a global supply chain network environment. Therefore, this research contributes to the logistics and supply chain network "body of knowledge" gap by exploring the supply chain disruptions, risk and uncertainty situation in theory, and logistics industry application in practice.

\section{Model description}

The RO approach used in this study is based on the model introduced by Mulvey et al. (1995), which incorporates a goal programming structure with a set of discrete scenarios with stochastic inputs as follows:

$$
\begin{array}{ll}
\text { Minimize } & c^{\mathrm{T}} x+d^{T} y \\
\text { s.t. } & \mathrm{Ax}=\mathrm{b} \\
& \mathrm{Bx}+\mathrm{Cy}=\mathrm{e} \\
& x \in R^{n_{1}}, \mathrm{y} \in R^{\mathrm{n}_{2}} \geq 0
\end{array}
$$

where $x$ denotes the vector of $n_{1}$ decision variables that are not conditioned by uncertain parameters and $y$ is the vector of $n_{2}$ control decision variables that are subject to uncertain parameters. Control variables are used to adjust the model to disruptions and changes.

Eqn. (2) presents the structural constraint whose coefficients are fixed and free of noise. Eqn. (3) denotes the control constraint for coefficients that are subject to noise. Eqn. (4), on the other hand, expresses the non-negativity conditions. In this notation, $R^{n_{1}}$ and $R^{\mathrm{n}_{2}}$ denote the 
set of design and control variables, respectively. Introducing $S=\{1,2, \ldots, s\}$ as a discrete set of scenarios, $\left\{d_{s}, B_{s}, C_{s}, e_{s}\right\}$ are identified as a RO model's coefficients with a probability of $p_{s}$ for the realisation of each scenario as captured,

$\left(\sum_{s} p_{s}=1\right)$. On this occasion, the optimal solution of the model will be robust with respect to optimality if it remains "close" to the optimal for any realisation of the scenario, termed as "solution robust", and the solution is also robust with respect to feasibility if it remains "almost" feasible for any realisation of $s$, and is termed as "model robust". Since it is unlikely that any solution to the problem remains both feasible and optimal for all scenarios, one is required to measure the trade-off between solution and model robustness. Taking $\left\{y_{1}, y_{2}, . ., y_{s}\right\}$ as a set of control variables and $\left\{z_{1}, z_{2}, . ., z_{s}\right\}$ as the error vectors under scenario $s$, the RO model is proposed:

$$
\begin{array}{ll}
\text { Minimize } & \sigma\left(x, y_{1}, . ., y_{s}\right)+\omega \rho\left(z_{1}, \ldots, z_{s}\right) \\
\text { s.t. } & \mathrm{Ax}=\mathrm{b} \\
& \mathrm{B}_{\mathrm{s}} \mathrm{x}+\mathrm{C}_{\mathrm{s}} \mathrm{y}+\mathrm{z}_{\mathrm{s}}=\mathrm{e}_{\mathrm{s}} \quad \forall s \in S \\
& x \geq 0, \mathrm{y}_{\mathrm{s}} \geq 0 \quad \forall s \in S
\end{array}
$$

In the realisation of multiple scenarios, the objective function is defined as a random variable with a value of $\varepsilon_{s}=c^{T} x+d^{T} y_{s}$, with probability $p_{s}$ and a mean value of $\sigma()=.\sum_{s} p_{s} \varepsilon_{s}$ according to the linear stochastic programming fundamentals. $\rho\left(z_{1}, \ldots, z_{s}\right)$ is identified as a feasibility penalty function which is used to penalise any violation of the control constraints under some of the scenarios. Eqn. (5) presents a multi-criteria objective with the first term for solution robustness and the second for model robustness. Here, $\omega$ is used to make a trade-off between solution 
and model robustness. In the aforementioned notation, the term $\sigma\left(x, y_{1}, . ., y_{s}\right)$ is considered as the mean value $\sigma($.$) plus a constant (\lambda)$ times of the variance. This function term, with recent consideration, can be formulated as follows:

$$
\sigma\left(x, y_{1}, . ., y_{s}\right)=\sum_{s} p_{s} \varepsilon_{s}+\lambda \sum p_{s}\left(\varepsilon_{s}-\sum_{s^{\prime}} p_{s^{\prime}} \varepsilon_{s^{\prime}}\right)^{2}
$$

As a replacement for the latest formulation, Yu and $\mathrm{Li}$ (2000) proposed an equivalent linear model that requires less computations compared to the previous quadratic model and adds fewer variables and constraints as shown below.

$$
\sigma\left(x, y_{1}, . ., y_{s}\right)=\sum_{s} p_{s} \varepsilon_{s}+\lambda \sum p_{s}\left|\varepsilon_{s}-\sum_{s^{\prime}} p_{s^{\prime}} \varepsilon_{s^{\prime}}\right|
$$

Though the model still has a nonlinear term, it can be converted to its linear equivalent by considering new non-negative variables and constraints. Yu and $\mathrm{Li}$ (2000) stated that a discrete linearisation approach is restricted due to the number of additive variables and constraints. Finally, they proposed the following linear framework for the RO:

$$
\begin{array}{ll}
\text { Minimize } & \sum_{s} p_{s} \varepsilon_{s}+\lambda \sum p_{s}\left[\left(\varepsilon_{s}-\sum_{s^{\prime}} p_{s^{\prime}} \varepsilon_{s^{\prime}}\right)+2 \theta_{s}\right] \\
\text { s.t. } & \varepsilon_{s}-\sum_{\mathrm{s}} p_{s} \varepsilon_{s}+\theta_{s} \geq 0 \\
& \theta_{s} \geq 0
\end{array}
$$

The latter formulation is applied in the proposed hybrid RO method to handle any occurrence of noise in the parameters. This formulation is used to extend to facility location modelling under both uncertainty and possibility. 


\subsection{Model assumptions}

Figure 1 represents a four-stage global supply chain network with the main components coming from the tier-1 suppliers to the plants, which produce the finished goods and distribute them to DCs for forward delivery to customers.

$$
\text { [Insert- Figure } 1 \text { here] }
$$

The supply chain network for the global apparel industry, as illustrated in Figure 1, comprises four players $(i, j, k, l)$ located in different countries, representing $i$ suppliers, $j$ producers, $k$ possible DCs and $l$ customers. The ROMILP model aims to find the best choice for a DC with the best allocation of the customers. Moreover, the optimal quantity produced for each assembly plant $\mathrm{j} \in \mathrm{J}$ under all strategies $\mathrm{n} \in \mathrm{N}$ and shipments for the raw materials shipped from a supplier $\mathrm{i} \epsilon \mathrm{I}$ to the plant $\mathrm{j} \epsilon \mathrm{J}$, plant to DC $\mathrm{k} \in \mathrm{K}$, and DC to customer zone $1 \epsilon \mathrm{L}$ under various transportation modes $\mathrm{t} \epsilon \mathrm{T}$ are proposed. Finally, the deviation for the violation of the mean and control constraints are determined under the set of market scenarios $\mathrm{s} \epsilon$ S.

In this model, it is assumed that brand manufacturers operate globally, with their suppliers, distributors and customers located in a worldwide network. A homogeneous product economy is considered implying that all manufacturers produce the same product, which is then shipped to the distributors, who, in turn, distribute the product to the end customers. The assembly line is unaffected by any ecological, operational or political interruption. However, the supply chain network is affected by the trade friction between the countries. All the players associated with the network follow a common currency. The direct ship method from a supplier to a customer is not applicable. Customer demand is not shared between the DCs. Each unit (batch) of semi-finished products/raw materials from the supplier is transformed into one finished product batch in the plant. 
Carbon emissions are assumed to be produced during production and in transit from supplier to plant (by land) and from DC to customer zones (by air/land). Transportation emission is considered negligible in the transportation from the plant to the DC (as it is through water which is the cleanest mode) and other nodes of the system. Such considerations are common in the literature on Green House Gas (GHG) emissions (KPITeam, 2016).

\subsection{Model notations}

\section{Parameters:}

$\mathrm{S}_{\mathrm{i}}$

$\mathrm{m}_{\mathrm{j}}, \mathrm{M}_{\mathrm{j}} \quad$ Production capacity for assembly plant $\mathrm{j}$ (minimum and maximum)

$\mathrm{q}_{\mathrm{k}}, \mathrm{Q}_{\mathrm{k}} \quad$ Throughput capacity for DC $\mathrm{k}$ (minimum and maximum)

$a_{j}, a_{j}, a_{k}$

Advance stock of raw materials and finished product in plant $\mathrm{j}$,

finished product in DC $\mathrm{k}$

$D_{l}^{s}$

Expected demand for market 1 under scenario s

$C_{i}^{s} \quad$ Unit cost of raw material for supplier $i$ under scenario $s$

$A_{j}^{s n} \quad$ Unit cost of production in plant $\mathrm{j}$ under strategy $\mathrm{n}$ and scenario s $(\$)$ 


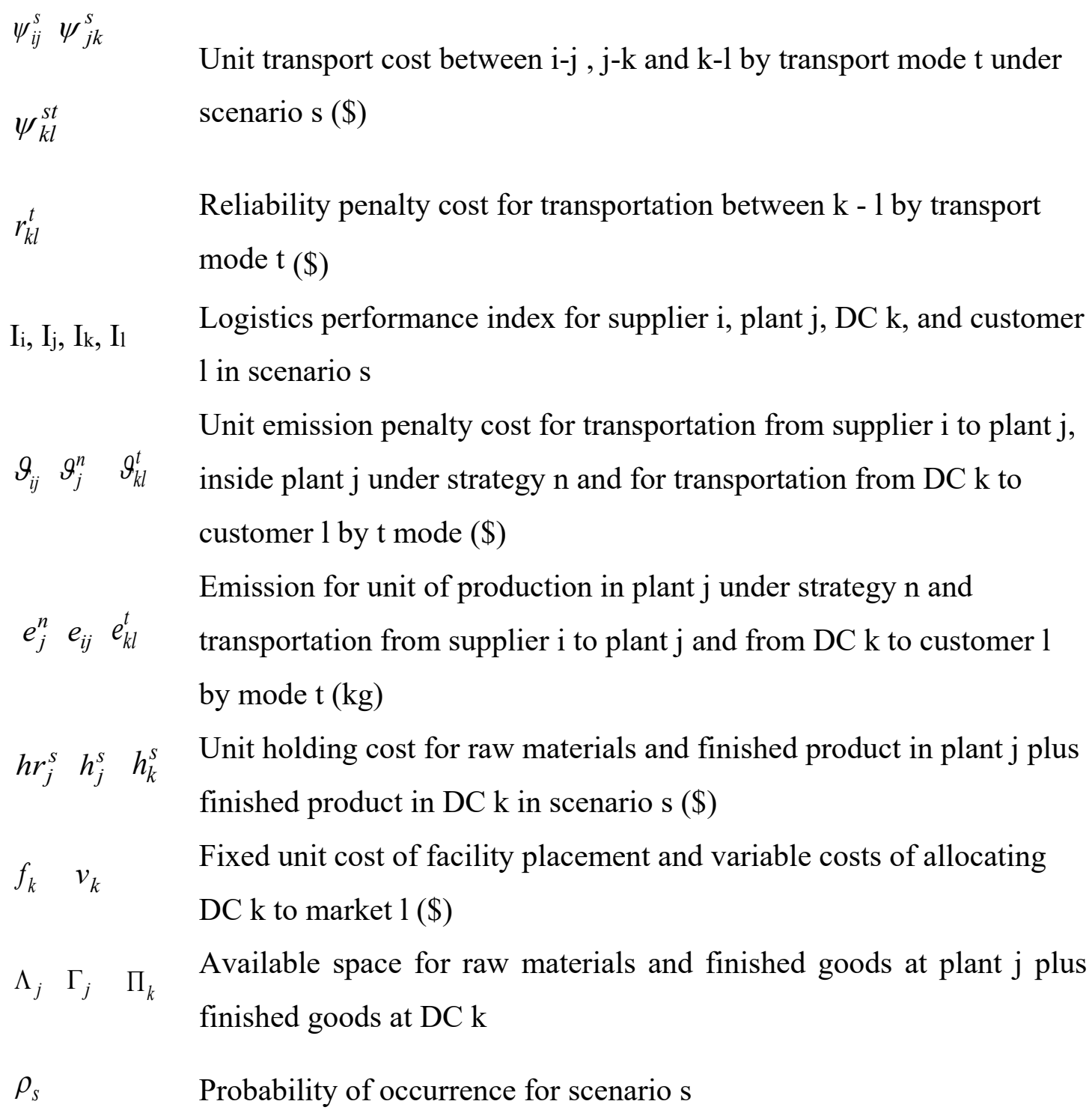


$\omega \quad$ Weight penalty for stock-out demand

$\varphi_{l}^{s} \varphi_{m}^{s} \varphi_{h}^{s} \quad$ Unit penalty cost for logistics friction per transaction between supplier-plant, plant-DC and DC-market (\$) Total upper bound emission $(\mathrm{kg})$

$I P C_{s}$ Incoming Part Cost for scenario s $(\$)$

$T A C_{s}$ Total Assembly Cost for scenario s (\$)

$I H C_{s} \quad$ Inventory Holding Cost for scenario s (\$)

$M M T C_{s} \quad$ Multi Modal Transportation Cost for scenario s (\$)

$T F C_{s} \quad$ Trade Friction Cost for scenario s $(\$)$

Variables

$x_{i j} \quad$ flow quantity of raw material between supplier i-plant $\mathrm{j}$

$y_{j k} \quad$ flow quantity of finished product plant $\mathrm{j}$-DC $\mathrm{k}$

$z_{k l}^{t} \quad$ flow quantity of finished product DC k-market 1 on transport mode $\mathrm{t}$

$z_{k l} \quad$ total flow quantity of finished product between DC k-market 1

$p_{j}^{n} \quad$ production rate at plant $\mathrm{j}$ under strategy $\mathrm{n}$

$p_{j} \quad$ total production rate at plant $\mathrm{j}$

$o_{k} \quad$ potential DC facility k should either be opened or not, 0-1 
DC facility $\mathrm{k}$ to serve particular customer zone 1 or not

$g_{l}^{s} \quad$ Over fulfilled stock at market 1 in scenario s at final stage

$\theta^{s} \quad$ Deviation for violation of mean under scenario $\mathrm{s}$

$\delta_{l}^{s} \quad$ Deviation for violation of control constraints for market $\mathrm{j}$ in scenario $\mathrm{s}$

\subsection{Robust Mixed Integer Linear Programming (ROMILP)}

Here the research derives a MILP model for the firm re-location decision problem to minimise the total cost of the supply chain network from supplier to customer.

\subsubsection{Objective function}

The model aims to minimise the Incoming Part Cost (IPC), Total Assembly Cost (TAC), Inventory Holding Cost (IHC), Multi Modal Transportation Cost (MMTC) and Trade Friction Cost (TFC) formulated under scenario s as follows:

$$
\begin{aligned}
I P C_{s} & =\sum_{\mathrm{i}} \sum_{\mathrm{j}} C_{i}^{s} x_{i j} \text { for all s. } \\
T A C_{s} & =\sum_{\mathrm{n}} \sum_{\mathrm{j}} A_{j}^{s n} p_{j}^{n}+\sum_{\mathrm{n}} \sum_{\mathrm{j}} e_{j}^{n} p_{j}^{n} \quad \text { for all s. } \\
I H C_{s} & =\sum_{\mathrm{j}} h r_{j}^{s}\left(-p_{j}^{n}+\sum_{i} x_{i j}+a r_{j}\right)+\sum_{\mathrm{j}} h_{j}^{s}\left(p_{j}^{n}-\sum_{k} y_{j k}+a_{j}\right)+\sum_{\mathrm{k}} h_{k}^{s}\left(\sum_{j} y_{j k}-\sum_{l} z_{k l}+a_{k}\right) \text { for all s }
\end{aligned}
$$


$M M T C_{s}=$

$\sum_{\mathrm{i}} \sum_{\mathrm{j}} \psi_{i j}^{s} x_{i j}+\sum_{\mathrm{j}} \sum_{\mathrm{k}} \psi_{j k}^{s} y_{j k}+\sum_{t} \sum_{\mathrm{k}} \sum_{1} \psi_{k l}^{s t} z_{k l}+\sum_{\mathrm{i}} \sum_{\mathrm{j}} \vartheta_{i j} x_{i j}+\sum_{t} \sum_{\mathrm{k}} \sum_{1} \vartheta_{k l}^{t} z_{k l}+\sum_{t} \sum_{\mathrm{k}} \sum_{1} r_{k l}^{t} z_{k l}$ for all s.

$T F C_{s}=\sum_{\mathrm{i}} \sum_{\mathrm{j}} \frac{\varphi_{l}^{s}}{I_{i} I_{j}} x_{i j}+\sum_{\mathrm{j}} \sum_{\mathrm{k}} \frac{\varphi_{m}^{s}}{I_{j} I_{k}} y_{j k}+\sum_{\mathrm{k}} \sum_{1} \frac{\varphi_{h}^{s}}{I_{k} I_{l}} z_{k l}$ for all s.

Eqn. (14) is the IPC at assembly plant $\mathrm{j}$, including the costs of the raw materials or semi-finished products of the suppliers. Eqn. (15) is the Total Assembly Cost consisting of the labour, quality and manufacturing costs at assembly centre $\mathrm{j}$ plus a penalty for carbon emissions at plant $\mathrm{j}$ that vary based on the chosen environmental production strategy. Eqn. (16) is the IHC including the holding costs of keeping raw materials or finished products in a plant besides the cost of keeping the finished products in a DC. Eqn. (17) is the MMTC including the transportation cost from supplier to plant, plant to DC, and from DC to customer plus the penalty costs for the logistics emissions between an applicable route and the chosen modes of transportation, and finally the penalty cost for the uncertainty, ranked according to the selected mode and distance parameters to meet end users' demand. Eqn. (18) is the TFC which is designed to measure the logistics difficulty based on the expected overall logistics performance index of the countries concerned, which reflects the efficiency of the customs clearance process, quality of trade- and transport-related infrastructure, ease of arranging competitively priced shipments, quality of logistics services, ability to track and trace consignments, and frequency with which the shipments reach the consignees within the scheduled time; the related trade friction unit penalty cost is scenario-based and is set to increase when getting close to the customer zone. 
The facility location costs are included in the fixed establishment cost and variable allocation costs for selected DC $\mathrm{k}$ under scenario s as formulated in Eqn. (19).

$$
\sum_{k} f_{k} o_{k}+\sum_{k} \sum_{l} v_{k} z_{k l}
$$

Then, the objective function of the ROMILP is developed as follows:

Minimize $\sum_{s} p_{s}\left(I P C_{s}+T A C_{s}+I H C_{s}+M M T C_{s}+T F C_{s}\right)+\sum_{k} f_{k} o_{k}+\sum_{k} \sum_{l} v_{k} z_{k l}$

$$
\begin{aligned}
& +\lambda \sum_{s} p_{s}\left(\left(I P C_{s}+T A C_{s}+I H C_{s}+M M T C_{s}+T F C_{s}\right)-\sum_{s^{\prime}} p_{s^{\prime}}\left(I P C_{s^{\prime}}+T A C_{s^{\prime}}+I H C_{s^{\prime}}+M M T C_{s^{\prime}}+T F C_{s^{\prime}}\right)+2 \theta_{s}\right) \\
& +\omega \sum_{s} \sum_{l} p_{s} \delta_{l}^{s}
\end{aligned}
$$

The first term in the Eqn. (20) denotes the mean of the function, the next term represents the fixed and variable costs of facility establishment, the third term shows the variance of the objective function, and the final term specifies the model robustness with respect to the degree of infeasibility considered in the control constraints.

\subsubsection{Constraints}

The objective function may fall into the feasible region subject to the supply, demand, capacity, inventory, multi-modal transport, trade-friction, uncertainty, and environmental and technology constraints, as formulated in Eqns. (21) to (39). 
$\sum_{i} x_{i j}-p_{j}+a r_{j} \leq \Lambda_{j} \quad \forall j \in J$

$p_{j}-\sum_{k} y_{j k}+a_{j} \leq \Gamma_{j} \quad \forall j \in J$

$\sum_{l} z_{k l} \leq \sum_{j} y_{j k} \quad \forall k \in K$

$\sum_{k} y_{j k} \leq p_{j} \quad \forall j \in J$

$p_{j} \leq \sum_{i} x_{i j} \quad \forall j \in J$

$\sum_{j} \sum_{n} e_{j}^{n} p_{j}^{n}+\sum_{i} \sum_{j} e_{i j} p_{i j}+\sum_{l} \sum_{k} \sum_{t} e_{k l}^{t} z_{k l}^{t} \leq \wp$

$\sum_{n} p_{j}^{n}=p_{j} \quad \forall j \in J$

$\sum_{t} z_{k l}^{t}=z_{k l} \quad \forall k \in K \quad l \in L$

$I P C_{s}+T A C_{s}+I H C_{s}+M M T C_{s}+T F C_{s}-\sum_{\mathrm{s}} p_{s}\left(I P C_{s}+T A C_{s}+I H C_{s}+M M T C_{s}+T F C_{s}\right)$

$+\theta^{s} \geq 0 \quad s \in S$ 
$x_{i j}, p_{j}^{n}, p_{j}, y_{j k}, z_{k l}^{t}, z_{k l}, \theta^{s}, \delta_{l}^{s} \geq 0 \quad, o_{k}, o_{k l} \in\{0,1\} \forall i \in I \quad j \in J \quad k \in K \quad l \in L \quad n \in N \quad t \in T \quad s \in S$

Constraint (21) controls the demand over and under-fulfilment for each customer under each scenario. Constraint (22) ensures that the total transaction of a supplier does not exceed the maximum supply capacity. Constraint (23) limits the quantity produced to the maximum production capacity of each plant and ensures that even if one plant is activated, it works at at least minimum capacity. Constraint (24) limits the throughputs of a selected DC to be between a minimum and maximum range. Constraint (25) limits the amount of input to each selected DC to the maximum and minimum system production level. Constraints (26) to (28) ensure the dedication of a particular DC to each customer and consider that if a DC facility is opened, it should serve at least one customer; in these constraints, a new binary variable $o k l$ for assigning DC $k$ to customer $l$ is identified to provide the linearity condition on the model when considering a single assignment. Otherwise, this constraint can be considered with explicit nonlinearity as shown in Eqn. (40).

$\prod_{k} z_{k l}=0 \quad \forall l \in L$

Constraints (29) to (31) limit the capacities for holding raw materials or finished products in the plant and finished products in DC, respectively. Constraints (32) to (34) ensure the flow balance between the nodes of the logistics system, while Constraint (35) limits the amount of emissions for the logistics system including the stationary emission produced in the plant and transportation emission produced through material or product delivery from supplier to plant and DC to customer based on the maximum acceptable emission bound. Constraint (36) ensures that the total production of each plant is equal to the sum of its production by different strategies. Constraint (37) sets that the total transaction between one set 
of DC and customer is equal to the sum of such transactions by different selected modes. Constraint (38) is an auxiliary constraint that provides the linearity of the RO according to Yu and Li (2000). Finally, Constraint (39) denotes the non-negative and binary variables. As described in Eqn. (40), the model includes a nonlinear component which sets the proposed model into the class of non-linear mixed integer programming. However, when adding the new variable of $o k l$ as shown in Eqns. (26) to (29) as a replacement, Eqn. (40) clearly provides the complete MILP model that can be precisely and efficiently solved through standard solvers, as reported in Yu and Li (2000), Leung et al. (2007), Mirzapour et al. (2011) and Belzahdi et al. (2017). The model has been solved in a real time global logistics network by applying a case study method as follows.

\section{Case study}

\subsection{Case description and modelling}

This section describes a global facility location problem for an apparel industry under various possibility states. The results are proposed for different cases of a certain decision-making process and with uncertainty incorporated in the parameters.

ABC Global Apparel's logistics system has 4 worldwide raw material suppliers: Chongqing (China), Dhaka (Bangladesh), Tirupur (India) and Karachi (Pakistan). These suppliers provide raw materials to the factories, with different capacities in Guangzhou (China) and Mumbai (India). The raw materials are usually sent to the production plants using road freight. The finished products are then shipped through sea freight 
comparatively with lower carbon emissions to the possible DCs in Dubai (UAE) and Djibouti (Djibouti). Finally, the finished products are sent out from the DCs to the global market zones in Ankara (Turkey), Jeddah (Saudi Arabia) and Cairo (Egypt) by selected means of transportation. Figure 2 shows the distribution of the facility locations associated with the global apparel supply chain network.

\section{[ Insert Figure 2 here]}

In this four-tiered global logistics and supply chain network, suppliers from Chongqing, Dhaka, Tirupur and Karachi have a supply capacity of $300,150,250$ and 150 batches of raw materials, respectively. The Guangzhou and Mumbai plants have production capacities in the range of 40 to 400 batches for finished goods; they also possess fixed storage capacities for keeping raw materials and finished products at 120 and 100 batches in plant 1, and 100 and 80 batches in plant 2, respectively. The potential DCs in Dubai and Djibouti, with a transaction capacity of 450 and 400 units, can be established at a cost of $\$ 70,000$ and $\$ 50,000$ with a total variable cost of $\$ 100$ and $\$ 130$ per batch of transaction, respectively. The other parameters related to the problem can be identified in Tables 2 to 6.

In this study, the unit batch transportation cost is developed based on the distance covered in unit cost for shipment per kilometre for each location and for each mode of transportation (land, water and air) under the associated scenarios. Distance is considered as the crow flies air distance in sea fright as this is the norm for calculation. For model solvability, the air freight rate is considered to be 1.7 times more expensive than the road freight by Full Container Load (FCL). These rate ratios are commonly used by logistics service providers such as DHL and UPS for their multi-modal shipments. Further, the sea-freight rate is considered to be 0.6 times lower than the road freight rate for the same volume. It is further assumed that land transport is two times cleaner than air transport according to the carbon-emission per batch of materials for every 
kilometre travelled. The sea freight emission is assumed to be zero carbon or carbon neutralised due to the nature of the shipment in model solvability aspects, as per Tables 2-4.

The data provided in Tables 2 to 6 are used for ABC global apparel logistics in all the scenarios and this dataset is configured from the literature and expert interviews. Table 2 reveals the market demand for each customer, the raw materials unit cost for each supplier, raw materials and product holding costs for each manufacturer and product holding costs at the DCs. Table 3 illustrates the production related costs including the manufacturing cost in each plant, emission amount and the penalty costs on the emissions related to two production strategies. Tables 4 and 5 describe the transportation costs in the supply chain together with the logistics emission amounts and penalty costs on those emissions for different routes and transportation options. Table 6 relates the penalty costs of logistics options under various geographical supplier, manufacturer and customer locations; these indices are identified from the World Bank's logistics performance index report (Arvis et al. 2018). In order to ensure maximum logistics priority on delivery to the customers, an associated penalty cost relevant to the trade friction between borders is considered while measuring the first mile and last mile delivery options that are closer to the supplier and customer zones, respectively. The unit penalty of TFC varies from $\$ 8$ to $\$ 10$ for transportation between the supplier and plant, from $\$ 16$ to $\$ 20$ from DCs to retailers, and from $\$ 35$ to $\$ 40$ for the delivery to the customers. In addition to these cost considerations, environmental consideration limits are set at an amount of carbon emissions equivalent to $3500 \mathrm{kgs}$.

\section{[ Insert Table 2 - Table 6 here]}

In addition, we consider four scenarios of the most probable market growth situations as follows: (1) boom, (2) good, (3) fair, and (4) poor, with occurrence probabilities of $45 \%, 25 \%, 17 \%$, and $13 \%$, respectively, as indicated by $\mathrm{Yu} \& \mathrm{Li}(2000)$. This assumption is common for scenario 
planning studies of logistics networks under realistic settings (Phelps et al. 2001). The ROMILP model is solved for optimality to minimise the associated logistics costs of IPC, TAC, IHC and TFC, plus facility location and allocation costs. The robust solution obtained is a trade-off between optimality and feasibility. Thus, the research proposes an optional logistics route cost structure from supplier to customer, by identifying possible DCs locations and order allocation options while meeting the demand uncertainty. The performance of the robust solution is then compared with other deterministic counterparts.

\subsection{Results and discussions}

All the computational results in this section are achieved by running the LINDO API 8.0-solver (Lindo Systems, 2019). In the ROMILP model, for market uncertainty, the values of $\lambda$ and $\omega$ are selected as 1 and 4500 in Table 6 in order to have the best model and solution robustness tradeoff as analysed. In addition, the paper considers no advance stock for the ABC facility location problem. The results are tabulated in Tables 7 to 9 and also depicted in Figures 3 to 6.

\section{[ Insert Table 7 - Table 9 here]}

In Table 7, the first column shows the potential locations of DCs in $k$ places. In the second and third columns, the aspects of opening or closing the DCs and the allocation of the DC to the best possible markets are marked by binary variables $[0,1]$. In the remaining columns, the number of product batches applicable to DCs while open and operational is recognised by the $\mathrm{CO}_{2}$ emissions produced. Finally, the associated cost components for each facility in the optimised solution are measured for all scenarios. Table 8 shows the optimised flow and route. The first panel presents the optimum assignment and number of raw material batches from supplier to plant. In the next column, the production strategies are 
stated as ' 1 ' for a green strategy and ' 2 ' for a price-efficient strategy; the production rates are identified in the plant for each strategy as optimising the related cost under uncertainty and satisfying the logistics system's upper bound on emissions as well. Next, the number of transactions and the corresponding routes are recognised from plant to DC and DC to customers; in the latter, the transportation is selected as ' 1 ' for land and ' 2 ' for air with different costs, reliability, capacity and emissions. Table 8 also shows the level of carbon emissions in the supply chain. The upper panel of Table 9 shows the market demands and over and under-fulfilment conditions according to the 4 market scenarios; however, the lower part shows the total system cost with related components.

Table 9 shows that the total demand fulfilled decreases in all markets when the scenario shifts from boom to poor (1 to 4$)$, and the same situation holds for all cost components; this trend is reversed for over-fulfilment. As shown in Tables 7 to 9, both DCs 1 and 2 are to be opened under RO with $\lambda=1$ and $w=4500$. Figures 3 to 5 present the comparative analyses of the two DCs.

[Insert Figure 3 - Figure 5 here]

Figure 3 compares the cost components related to the two opened DCs (Dubai and Djibouti) in all 4 scenarios in the optimised solution; for example, the MMTC under scenario 1 (MMTC1) costs $\$ 314,650$ for the Dubai facility compared with $\$ 215,585$ in Djibouti. However, the TAC is about the same in both facilities under all scenarios with a non-increasing trend from Scenarios 1 to 4 , while the Dubai DC has an advantage over the Djibouti DC on the TFC. Figure 3 suggests that the transportation and strategic location of the DC is critical.

Figure 4 depicts the demand conditions of under and over fulfilment related to each DC when assigned to the best possible markets. In all four scenarios, under-fulfilment is found to be the highest in the Dubai facility when there is a boom (scenario 1). Over-fulfilment, on the other 
hand, is more pronounced in scenario 4 for the Dubai DC. Figure 5 compares the two facilities from the environmental related characteristics including logistics and production emissions. When we again compare Djibouti DC with Dubai DC for environmental considerations, Djibouti seemed to be a better trade-off compared to Dubai; however, the volume of business connected to the Dubai DC enables the preference.

\section{[ Insert Figure 6 here]}

Figure 6 provides a trade-off between the solution robustness and model robustness, whereby increasing the stock-out weight penalty diminishes the under fulfilled demand, although the total cost variance increases. This is done to ensure the robust solution feasibility and optimality. However, the values of $\lambda=1$ and $\omega=4500$ are a superior trade-off as the under-fulfilment percentage is $6 \%$ with a mean variance of $\$ 63,645$ from the total cost of $\$ 1,766,000$.

\section{[ Insert Figure 7 here]}

In Figure 7, the effect of changing the weight on the facility location and allocation decisions is analysed for three values of w (2700, 2900, and our selected 4500). The results present different facility decisions in the three examples that prove model sensitivity to the favoured stock-out risk penalty parameter of $\mathrm{w}=4500$. Overall, the Dubai DC benefits from a sustainable business standpoint connecting all the sources and destinations.

\subsection{Comparison of results performance}

The results of the proposed RO model are compared against 4 deterministic approaches. In all instances, the demands are completely satisfied, and an optimal solution is found for the scenarios. However, the RO model yielded a smaller than expected cost value (see Table 10). 


\section{[ Insert Table 10 here]}

From Table 10, the expected value of the total cost for the robust solution of the 4 scenarios compared to the 4 deterministic solutions (D1D4) is the lowest. In addition, the RO solution is closest to the optimum in terms of the total cost as compared to the other most probable solutions under Scenarios 1 and 2 that have a total probability of occurrence of $70 \%$. In this comparison, the costs are calculated based on the total cost of the model, including the IPC, TAC, MMTC, TFC, variable and fixed facility costs plus the shortage and overage costs. The unit shortage cost is set at $\mathrm{w}=4500$ in line with the RO model and the unit overage cost at the final stage is set at $20 \%$ higher than the maximum unit holding cost in the DC. While the total saving varies for the scenarios, the RO solution clearly outweighs the rest.

\section{Managerial Implications}

As demonstrated in Table 7 and Figure 3, for the optimal solution, both DCs are chosen to be opened in the proposed locations. In the optimised allocation, the Dubai DC is selected to serve markets in Turkey by air. The Djibouti DC is assigned to the Saudi Arabian and Egyptian markets using land transport. Such an approach of facility location and allocating markets by considering $\lambda$ and $\omega$ reduces the risks of escalating costs and of not fully satisfying demand, as shown in Table 10. The model and solution thus enable logistics service providers and business organisations that are networked under these supply and market conditions. The research also supports supply chain planners to better plan for 
cost, environmental friendliness, trade friction conditions, and geo-political risks and uncertainties. Figure 8 shows the optimised network design, logistics strategies and transport modes.

\section{[ Insert Figure 8 here]}

Figure 9 exhibits the current global container traffic captured from a live Dubai Trade container traffic system, highlighting the red spots of shipment vessels that move along the OBOR corridor. Other implications recommended for managers are: practice green target and related alternative production/transportation policies, achieve trade-off between reliability, cost, risk and green environment compliance for facility location decisions, and identify an optimal solution based on various multi-objectives in terms of the expected total cost saving while satisfying the demand in an uncertain market.

\section{Conclusion}

This research paper has proposed a Hybrid RO and MILP method linking the social constraints with the modern supply chain constraints under possibility and probability situations. Supply chain managers can use ROMILP to test the cost benefit trade-offs with respect to the green facility location and supply chain cost decisions when operating under uncertainty.

\subsection{Theoretical contribution}

The model can facilitate decision making aspects for the possibility of establishing or relocating a distribution facility in the global supply chain network. This is significant because this paper combines the possibilities and probabilistic scenarios for a supply chain network by proposing 
the ROMILP method. As a result, this research challenges the traditional assumptions associated with the supply chain network design and imposes decision variables and constraints that are connected to disruptive robust optimisation. Thus, the research contributes to the supply chain and logistics network theory by the addition of new dimensions, variables and constraints under disruptive conditions. A case study has been solved on a global supply chain network along the OBOR corridor and is able to understand the cost implications of the current situation and to anticipate the impact of ongoing OBOR developments. Despite the supply chain network side theoretical contribution the research add value to the 'disruptive innovation theory' to prepare resilient strategies at the face of uncertainty as follows.

Earlier, Kaplan (1964) said, "A new theory requires its own terms and generates its own laws: the old concepts are not merely reorganized, but reconstituted, the old laws not just connected, but given a new meaning" (p. 297). In practice, technological adoption applications under disruptions in supply chains have the capability to challenge some existing business theories and to add a wholly new dimension to the existing theory, as discussed by Kaplan (1964). For organisations to be able to extend their competitive advantage, resilience business strategies, resource allocations, new facility arrangement and infrastructural arrangements are of paramount importance. The evolution of logistics networks and process innovation are a transformative process. According to Industry 4.0 disruptions, the supply chain-wide stakeholder reengineering and transformation would be required for effective blockchain implementation (Zhu et al., 2018). This has been echoed by Dolgui et al. (2020), who state that blockchain adoption in supply chains has the capability to change some of the traditional constructs, and the relationships in the existing theory may have to be revisited to determine their applicability. As discussed, the article is grounded on "disruptive innovation theory" in which the innovation is more on supply chain processes rather than product or service innovation (Christensen et al., 2015). As we anchored the research 
on "disruptive innovation theory", the research has added to the theoretical body of knowledge and opened up the door for academics and practitioners to extend further research in this space. Especially during the COVID-19 pandemic, where the industry growth formulae have been changed and disrupted, the requirement and benefits of this research are multi-faceted, critical and essential.

\subsection{Practical contributions}

Since the OBOR developments are currently highly fragmented across Asian countries due to geo-political conflicts and challenges, the impact of the proposed corridor and expected benefits are yet to be measured. Therefore, the research proposes a number of recommendations which could be used by practitioners to make decisions under uncertainty and for policy makings. Because emerging markets possess greater market opportunities, the potential benefits of disruptive innovation are substantial if appropriately reaped. Since only a few organisations globally are advanced in implementing new data analytics (Fosso Wamba, 2019; de Camargo Fiorini et al., 2019) and blockchain related digital twin technology initiatives, the recommendations can be useful for other companies in the Middle East and elsewhere who wish to implement such robust disruptive models that can aid logistics decision making aspects in their business processes. As we see a wave of digital transformation moves in the vertical logistics industry, the need for robust resilient decision-making tools or solution approaches are essential. C-suite executives of third-party logistics firms need timely intervention, as well as changes in strategies, planning and operational execution based on the cost, service and risk hedged realistic actions and supply chain location decisions.

\subsection{Future research opportunities}


This research can be extended by adding capacity considerations on storage and related warehousing, transportation loads and also by considering political risks and trade barriers of the OBOR corridor. Thus, the research expands future research directions to be able to assess how the proposed OBOR mentioned in global container traffic would impact the current container traffic both worldwide and for the countries participating in the OBOR corridor mega project. Because this research addresses one of the most important aspects of the complex robust logistics network optimisation in practice, the article focuses on how non-linear thinking in terms of OBOR decision variables and related adaptive ecosystems make this research more innovative, relevant to the industry and futuristic. Thus, the novelty and contributions of this research create pathways for future researchers in this era of disruptive supply chain digitalisation.

\section{Acknowledgements}

The authors would like to acknowledge the comments provided by three anonymous (double blind) reviewers, whose comments enhanced the quality of this paper. The authors would like to thank the University of Wollongong in Dubai for partially supporting the research through a university research grant and Ms Golnar Behzadi for supporting the data collection process. The authors would also like to thank an anonymous proofreader for proofreading the article, which improved the readability of the paper.

\section{References}


Aliev, T, M. (2016), "The Economic Belt of the Eurasian Integration: a report on the ways of implementing the integration project of the integration of the Eurasian Economic Union and of the Silk Road Economic Belt”, pp.160.

Anciaux, D., and Kun, Y. (2007), "Green supply chain. intermodal transportation modelling with environmental impacts", paper presented at the European Transport Conference, October, 2007, Leiden, Netherlands, pp.17-19

Aoyama. R (2016), ““'One Belt, One Road”: China’s new global strategy”, Journal of Contemporary East Asian Studies, Vol.5 No. 2, pp.3-22

Arvis, J.F., Mustra, M.A, Ojala, L., Shepherd, B., and Saslavsky, D. (2018), “The Logistics Performance Index and Its Indicators”, World Bank Annual Report., pp.230.

Atamtürk, A., and Zhang, M. (2007), “Two-stage robust network flow and design under demand uncertainty”, Operations Research, Vol.55, pp.662-673.

Baghalian, A., Rezapour, S., and Farahani, R.Z. (2013), "Robust supply chain network design with service level against disruptions and demand uncertainties: a real-life case", European Journal of Operational Research, Vol. 227 No. 1, pp.199-215.

Bai, D., Carpenter, T., and Mulvey, J. (1997), "Making a case for robust optimization models”, Management Science, Vol. 43 , pp.895-907.

Behzadi, G., O'Sullivan, Justin, M., Olsen, T. and Zhang, A. (2017), "Robust and resilient strategies for managing supply disruptions in an agribusiness supply chain", International Journal of Production Economics, Vol. 191, pp.207-220

Behzadi, G.,Sundarakani, B., and Mardaneh, E. (2013), "Robust optimisation model for the cold food chain logistics problem under uncertainty", International Journal of Logistics Economics and Globalisation, Vol. 5 No. 3, pp.167-179. 
Bertsimas, D. J. (1989). Traveling salesman facility location problems. Transportation science, Vol.23 No.3, pp.184-191.

Ben Abdelaziz F. and Masri H. (2005), “Stochastic programming with fuzzy probability distribution”, European Journal Operational Research,

Vol. 162 No. 3, pp.619-629.

Ben-Tal, A., and Nemirovski, A. (1998), "Robust convex optimization”, Mathematics of Operations Research, Vol. 23 No. 4, pp.769-805.

Benyoucef, L., Xie, X., Tanonkou, G.A. (2013), "Supply chain network design with unreliable suppliers: a Lagrangian relaxation-based approach”, International Journal of Production Research, Vol. 51 No. 21, pp.6435-6454.

Brown, P.A., and Gibson, D.F. (1972), “A quantified model for facility site selection application to multi plant location problem”, AIIE Transactions, Vol. 4 No. 1, pp.1-10.

Castillo, I., Ingolfsson, A., and Sim, T. (2009), "Social optimal location of facilities with fixed servers, stochastic demand and congestion", Production and Operations Management, Vol. 18 No. 6, pp.721-736.

Chan, Y., \& Baker, S. F. (2005). The multiple depot, multiple traveling salesmen facility-location problem: Vehicle range, service frequency, and heuristic implementations. Mathematical and Computer Modelling, Vol. 41 No.8-9, pp.1035-1053.

Cordeau, J. F., Pasin, F., and Solomon, M.M. (2006), “An integrated model for logistics network design”, Annals of Operations Research, Vol. 144, pp.59-82.

Davis, F. D. (1986), “A Technology Acceptance Model for Empirically Testing New End-User Information Systems: Theory and Results”, Sloan School of Management, Massachusetts Institute of Technology, Cambridge, MA. 
De Rosaa, V., Gebhard, M., Hartmann, E., and Wollenweber, J. (2013), "Robust sustainable bi-directional logistics network design under uncertainty", International Journal of Production Economics, Vol. 145 No. 1, pp.184-198.

Dolgui, A., Ivanov, D., Potryasaev, S., Sokolov, B., Ivanova, M. and Werner, F. (2020), “Blockchain-oriented dynamic modelling of smart contract design and execution in the supply chain", International Journal of Production Research, Vol. 58 No. 7, pp.2184-2199.

Dubey, R., A. Gunasekaran, S. J. Childe, S. F. Wamba, D. Roubaud, and C. Foropon. (2019a), "Empirical Investigation of Data Analytics Capability and Organizational Flexibility as Complements to Supply Chain Resilience", International Journal of Production Research. doi:10.1080/00207543.2019.1582820

Dubey, R., A. Gunasekaran, S. J. Childe, C. Blome, and T. Papadopoulos. (2019b), "Big Data and Predictive Analytics and Manufacturing Performance: Integrating Institutional Theory, Resource-Based View and Big Data Culture”, British Journal of Management, Vol. 30 No. 2 , pp.341-361.

Erickson, R.A., and Wasylenko, M. (1980), "Firms' relocation and site selection in suburban municipalities", Journal of Urban Economics, Vol. 8, pp.69-85

Escudero, L.F., Kamesam, P.V., King, A., and Wets, J.B. (1993), "Production planning visa scenario modelling”, Annals of Operations Research, Vol. 43, pp.311-335.

Gammelgaard, B. (2019), "Congratulations to IJLM on its first 30 years", The International Journal of Logistics Management, Vol. 30 No. 1, pp. $2-7$. 
Geoffrion, A.M., and Graves, G.W. (1974), “Multi-commodity distribution design by Benders decomposition”, Management Science, Vol. 20, pp.822-844.

Gülpınar, N., Pachamanova, D., and Çanakoğlu, E. (2013), "Robust strategies for facility location under uncertainty", European Journal of Operational Research, Vol. 225 No. 1, pp.21-35.

Gutierrez, G.J., and Kouvelis, P. (1995), “A robustness approach to international outsourcing”, Annals of Operations Research, Vol. 59 No. 1, pp.165-193.

Hasani, A., Zegordi, S.M., and Nikbakhsh, E. (2012), "Robust closed-loop supply chain network design for perishable goods in agile manufacturing under uncertainty", International Journal of Production Research, Vol. 50 No. 16, pp.4649-4669.

Hassanzadeh-Amin, S., and Zhang, G. (2013), “A multi-objective facility location model for closed-loop supply chain network under uncertain demand and return”, Applied Mathematical Modelling, Vol. 37 No. 6, pp.4165-4167.

Hofmann, E., U. M. Strewe, and N. Bosia. (2017), Supply Chain Finance and Blockchain Technology: The Case of Reverse Securitisation, Springer, Berlin.

Hofmann, E., U. M. Strewe, and N. Bosia. (2018), Supply Chain Finance and Blockchain Technology, Springer, Berlin, pp.77-87.

Ivanov, D. (2020), "Predicting the impacts of epidemic outbreaks on global supply chains: A simulation-based analysis on the coronavirus outbreak (COVID-19/SARS-CoV-2) case”, Transportation Research Part E: Logistics and Transportation Review, Vol. 136, 101922. 
Ivanov, D., A. Dolgui, and B. Sokolov. (2019), “The Impact of Digital Technology and Industry 4.0 on the Ripple Effect and Supply Chain Risk Analytics", International Journal of Production Research, Vol. 57 No. 2, pp.829-846.

Jayaraman, R., Colapinto, C., La Torre, D. and Malik, T. (2015), "Multi-criteria model for sustainable development using goal programming applied to the United Arab Emirates", Energy Policy, Vol. 87, pp.447-454.

Kacem, I., Sahnoune, M. and Schmit G. (2016), "Strongly Fully Polynomial Time Approximation Scheme for the Weighted Completion Time Minimization Problem on Two-Parallel Capacitated Machines”, Operations Research, Vol. 51 No. 4, pp.1177-1188

Kacem, I., Sahnoune, M. and Schmit G. (2018), "Strongly Fully Polynomial Time Approximation Scheme for the Weighted Completion Time Minimization Problem on Two-Parallel Capacitated Machines”, Operations Research, Vol. 51 No. 4, pp.1177-1188.

Kahramana, C., Ruanb, D., and Doğana, I. (2003), “Fuzzy group decision-making for facility location selection”, Information Sciences, Vol. 157, pp.135-153.

Kanyalkar, A.P., and Adil, G.K. (2010), “A robust optimization model for aggregate and detailed planning of a multi-site procurement-productiondistribution system”, International Journal of Production Research, Vol. 48 No. 3, pp.635-656.

Kaplan, A. (1964), The conduct of inquiry, Chandler, San Francisco.

KPI-Team (2016), "Sustainability Measures for Logistical Activities: CO2 emission and energy reduction”, Consumer Goods Forum's 2016 Future Supply Chain Platform, Vol. 1 No. 1, 1-26.

La Torre, D. (2003), “On generalized derivatives for C1,1 vector optimization problems”, Journal of Applied Mathematics, Vol. 7, pp.365-376. 
Lambert, D. M., Knemeyer, A. M., \& Gardner, J. T. (2004), “Supply chain partnerships: model validation and implementation”, Journal of Business Logistics, Vol. 25 No. 2, pp.21-42

Leung, S.C.H., Tsang, S.O.S., Ng, W.L., and Wu, Y. (2007), “A robust optimization model for multi-site production planning problem in an uncertain environment”, European Journal of Operational Research, Vol. 181 No. 1, pp.224-238.

Liao-Troth, S., Thomas, S., \& Fawcett, S. E. (2012), “Twenty years of IJLM: evolution in research”, The International Journal of Logistics Management, Vol. 23 No. 1, pp.4-30.

Marchet, G., Melacini, M., Perotti, S., Sassi, C., Tappia, E. (2017), "Value creation models in the 3PL industry: what 3PL providers do to cope with shipper requirements", International Journal of Physical Distribution \& Logistics Management, Vol. 47 No. 6, pp.472-494

Masri H. (2017), “A multiple stochastic goal programming approach for the agent portfolio selection problem”, Annals of Operations Research, Vol. 251 No. 1, pp.179-219.

Meloa, b, M.T., Nicke, S., and Saldanha-da-Gama, F. (2009), "Facility location and supply chain management - A review", European Journal of Operational Research, Vol. 196, pp.401-412.

Mirzapour Al-e-hashem, S.M.J., Makeli, H., and Aryanezhad, M.B. (2011), "Multi-objective robust optimization model for multi-product multisite aggregate production planning in a supply chain under uncertainty”, International Journal of Production Economics, Vol. 134, pp.28-42.

Moses, L., and Williamson, H.F. (1967), “The location of economic activity in cities”, American Economic Review, Vol. 57, pp.211-222. 
Mulvey, J.M., and Ruszcczynski, A. (1995), “A new scenario decomposition method for large-scale stochastic optimization”, Operations Research, Vol. 43 No. 3, pp.477-490.

Mulvey, J.M., Vanderbei, R.J., and Zenios, S.A. (1995), “Robust optimization of large scale systems”, Operations Research, Vol. 43 No. 2, pp.264281.

Nair, A. and Reed-Tsochas, F. (2019), "Revisiting the complex adaptive systems paradigm: leading perspectives for researching operations and supply chain management issues", Journal of Operations Management, Vol. 65 No. 2, pp.80-92

Nair, A., Yan, T., Ro, Y., Oke, A., Chiles, T. and Lee, S. (2016), "How environmental innovations emerge and proliferate in supply networks: a complex adaptive systems perspective", Journal of Supply Chain Management, Vol. 52 No. 2, pp.66-86.

Nilsson, F. and Christopher, M. (2018), "Rethinking logistics management - towards a strategic mind-set for logistics effectiveness and innovation”, Emergence: Complexity and Organization, 30 June (last modified: 24 February 2019), Edition 1, Vol. 20 No. 2 , pp.1-24.

Petrović, G. S., Madić, M., \& Antucheviciene, J. (2018), “An approach for robust decision making rule generation: Solving transport and logistics decision making problems", Expert Systems with Applications, Vol. 106, pp.263-276.

Phelps, R., Chan, C., and Kapsalis, S. (2001), "Does scenario planning affect performance? Two exploratory studies", Journal of Business Research, Vol. 51 No. 3, pp.223-232.

Ploberger. C, (2017), “One Belt, One Road-China’s new grand strategy”, Journal of Chinese Economic Business Studies, Vol. 15, pp.289-305 
Rahmaniani, R., Saidi-Mehrabad, M., and Ashouri, H. (2013), "Robust capacitated facility location problem: optimization model and solution algorithms", Journal of Uncertain Systems, Vol. 7 No. 1, pp.22-35.

Rakhmangulov A., Sładkowski A., Osintsev N., Kopylova O., Dyorina N. (2018), "Sustainable Development of Transport Systems for Cargo Flows on the East-West Direction", Sładkowski A. (Ed.), Transport Systems and Delivery of Cargo on East-West Routes. Studies in Systems, Decision and Control, Springer, Cham.

Saberi, S., Kouhizadeh, M., Sarkis, J. and Shen, L. (2019), "Blockchain technology and its relationships to sustainable supply chain management”, International Journal of Production Research, Vol. 57 No. 7, pp.2117-2135.

Sarkis, J., Cohen, M.J., Dewick, P. and Schröder, P. (2020), “A Brave New World: Lessons from the COVID-19 Pandemic for Transitioning to Sustainable Supply and Production. Resources, Conservation, and Recycling”, In-press

Sengupta, J.K. (1991), "Robust solutions in stochastic lines programming”, JORSA, Vol. 42 No. 10, pp.857-870.

Simchi-Levi, D., Kaminsky, P., and Simchi-Levi, E. (2004), Managing the Supply Chain: The definitive guide for the business professional, McGraw-Hill, New York.

Snyder, L.V. (2006), “Facility location under uncertainty: a review”, IIE Transactions, Vol. 38 No. 7, pp.537-554.

Snyder, L.V., and Daskin, M.S. (2006), “Stochastic, p-robust location problems”, IIE Transactions Vol. 38, pp.971-985.

Srivastava, S. (2007), “Green supply-chain management: A state-of-the-art literature review”, International Journal of Management Review, Vol. 9 No. 1, pp. $53-80$. 
Sundarakani, B., and Van Over, D. (2010), "Robust decision model for facility location in a global supply chain network", paper presented at POMS 21st Annual Conference, 7-10 May, Vancouver, Canada, No. 015-0155.

Sundarakani, B., Souza, R., Goh, M., Wagner, S.M., and Manikandan, S. (2010), "Modelling carbon footprints across the supply chain", International Journal of Production Economics, Vol. 128, pp.43-50.

Touboulic, A., Matthews, L. and Marques, L. (2018), “On the road to carbon reduction in a food supply network: a complex adaptive systems perspective", Supply Chain Management: An International Journal, Vol. 23 No. 4, pp.313-335.

Wachter, M.L. (1978), "Wage determination in a local labour market: A study of the Boston labour market”, Journal of Human Resources, Vol. 7, pp.87-103.

Wamba, S, W., Jean Robert Kala Kamdjoug, Ransome EpieBawack \& John G. Keogh. (2020), "Bitcoin, Blockchain and Fintech: a systematic review and case studies in the supply chain”, Production Planning \& Control, Vol. 31 No. 2/3, pp.115-142.

$\mathrm{Wu}, \mathrm{Y}$. (2006), "Robust optimization applied to uncertain production loading problems with import quota limits under the global supply chain management environment”, International Journal of Production Research, Vol. 44 No. 5, pp.849-882.

Yang, L., Ji, X., Gao, Z., and Li, K-P. (2007), "Logistics distribution centres location problem and algorithm under fuzzy environment”, Journal of Computational and Applied Mathematics, Vol. 208 No. 2, pp.303-315.

Yu, C.S., and Li, H.L. (2000), “A robust optimization model for stochastic logistic problems”, International Journal of Production Economics, Vol. 64, pp.358-379. 
Yu, G., Li, F., and Yang, Y. (2017), "Robust supply chain networks design and ambiguous risk preferences”, International Journal of Production Research, Vol. 55 No. 4, pp.1168-1182.

Zhang, M., and Yang, J. (2007), "Optimization modelling and algorithm of facility location problem in perishable commodities emergency system”, paper presented at Third International Conference on Natural Computation 1, 24-27 August, Haikou, pp.246-250.

Zhu, S., J. Song, B. T. Hazen, K. Lee, and C. Cegielski. (2018), "How Supply Chain Analytics Enables Operational Supply Chain Transparency: An Organizational Information Processing Theory Perspective.” International Journal of Physical Distribution \& Logistics Management, Vol. 48 No. 1, pp. $47-68$ 



\section{List of Tables}

Table 1. Features of proposed model vs. existing RO models

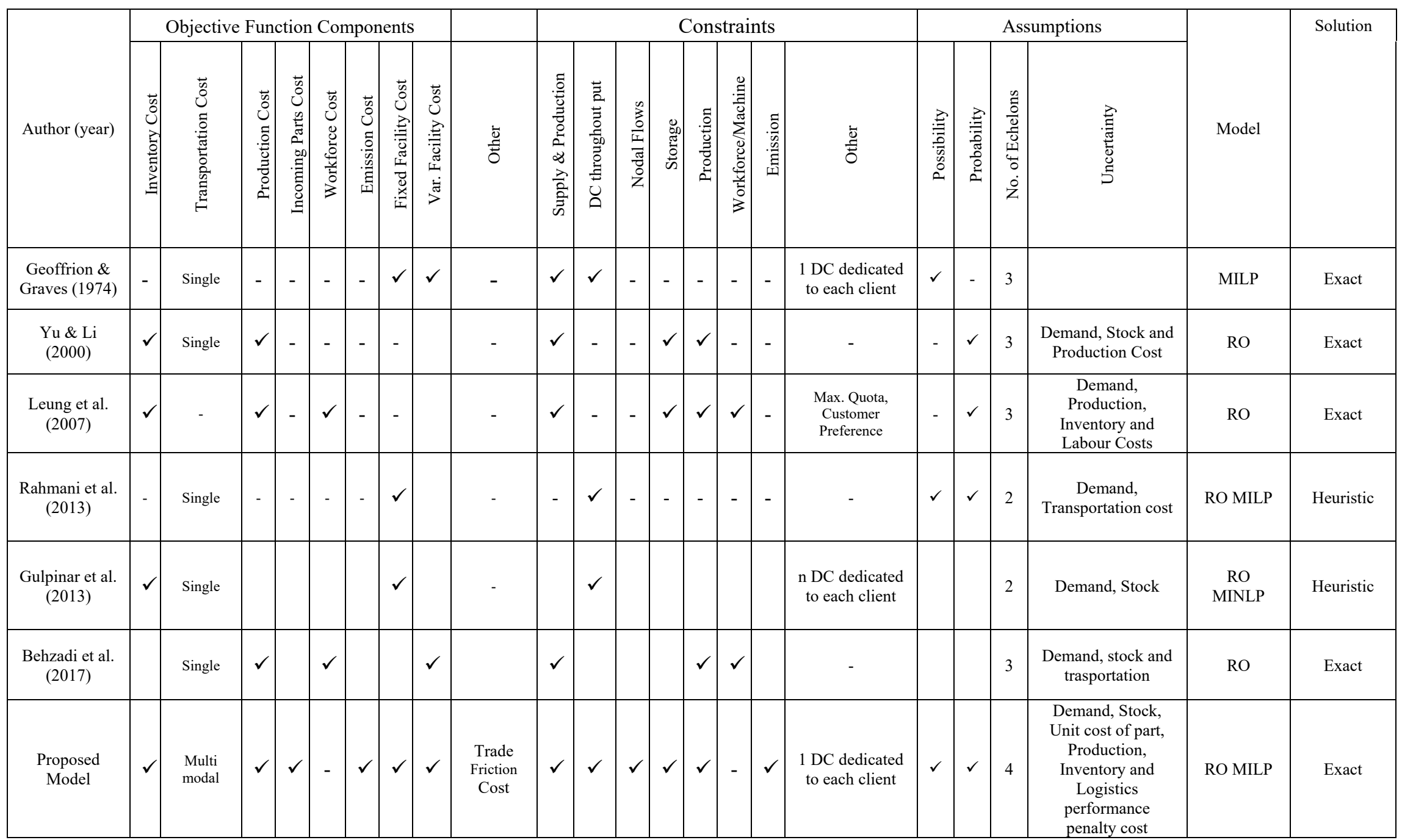


Table 2. Market demand (batches) and unit costs under market scenarios

\begin{tabular}{|c|c|c|c|c|c|c|c|c|c|c|c|c|c|}
\hline \multicolumn{14}{|c|}{ Market demand (batches) and unit costs under market scenarios } \\
\hline \multirow[t]{2}{*}{ Scenario } & \multicolumn{3}{|c|}{ Demand } & \multicolumn{10}{|c|}{ Unit cost (\$) } \\
\hline & & & & \multicolumn{4}{|c|}{$\begin{array}{l}\text { Raw } \\
\text { supply }\end{array}$} & \multicolumn{2}{|c|}{$\begin{array}{l}\text { Raw material } \\
\text { holding }\end{array}$} & \multicolumn{2}{|c|}{$\begin{array}{l}\text { Finished } \\
\text { goods } \\
\text { holding }\end{array}$} & \multicolumn{2}{|c|}{$\begin{array}{l}\text { Finished } \\
\text { goods } \\
\text { holding }\end{array}$} \\
\hline & \multicolumn{3}{|c|}{ Market } & \multicolumn{4}{|c|}{ Supplier } & \multicolumn{2}{|c|}{ Plant } & \multicolumn{2}{|c|}{ Plant } & \multicolumn{2}{|l|}{$\mathrm{DC}$} \\
\hline & 1 & 2 & 3 & 1 & 2 & 3 & 4 & 1 & 2 & 1 & 2 & 1 & 2 \\
\hline \multirow[t]{2}{*}{1} & 40 & 18 & 20 & 27 & 32 & 35 & 30 & \multirow[t]{2}{*}{75} & \multirow[t]{2}{*}{60} & \multirow[t]{2}{*}{86} & \multirow[t]{2}{*}{91} & \multirow[t]{2}{*}{125} & \multirow[t]{2}{*}{100} \\
\hline & 0 & 8 & 0 & 0 & 0 & 0 & 0 & & & & & & \\
\hline \multirow[t]{2}{*}{2} & 35 & 16 & 18 & 25 & 30 & 32 & 28 & \multirow[t]{2}{*}{65} & \multirow[t]{2}{*}{52} & \multirow[t]{2}{*}{73} & \multirow[t]{2}{*}{78} & \multirow[t]{2}{*}{113} & \multirow[t]{2}{*}{90} \\
\hline & 0 & 1 & 5 & 0 & 0 & 8 & 8 & & & & & & \\
\hline \multirow[t]{2}{*}{3} & 28 & 15 & 16 & 24 & 29 & 32 & 27 & \multirow[t]{2}{*}{60} & \multirow[t]{2}{*}{48} & \multirow[t]{2}{*}{69} & \multirow[t]{2}{*}{75} & \multirow[t]{2}{*}{109} & \multirow[t]{2}{*}{86} \\
\hline & 0 & 0 & 0 & 0 & 0 & 0 & 0 & & & & & & \\
\hline \multirow[t]{2}{*}{4} & 2 & 14 & 13 & 23 & 28 & 31 & 25 & \multirow[t]{2}{*}{55} & 40 & 66 & 68 & 104 & 78 \\
\hline & 0 & 3 & 0 & 5 & 0 & 0 & 7 & & & & & & \\
\hline
\end{tabular}


Table 3. Production, emission penalty unit costs, and carbon emissions under different scenarios

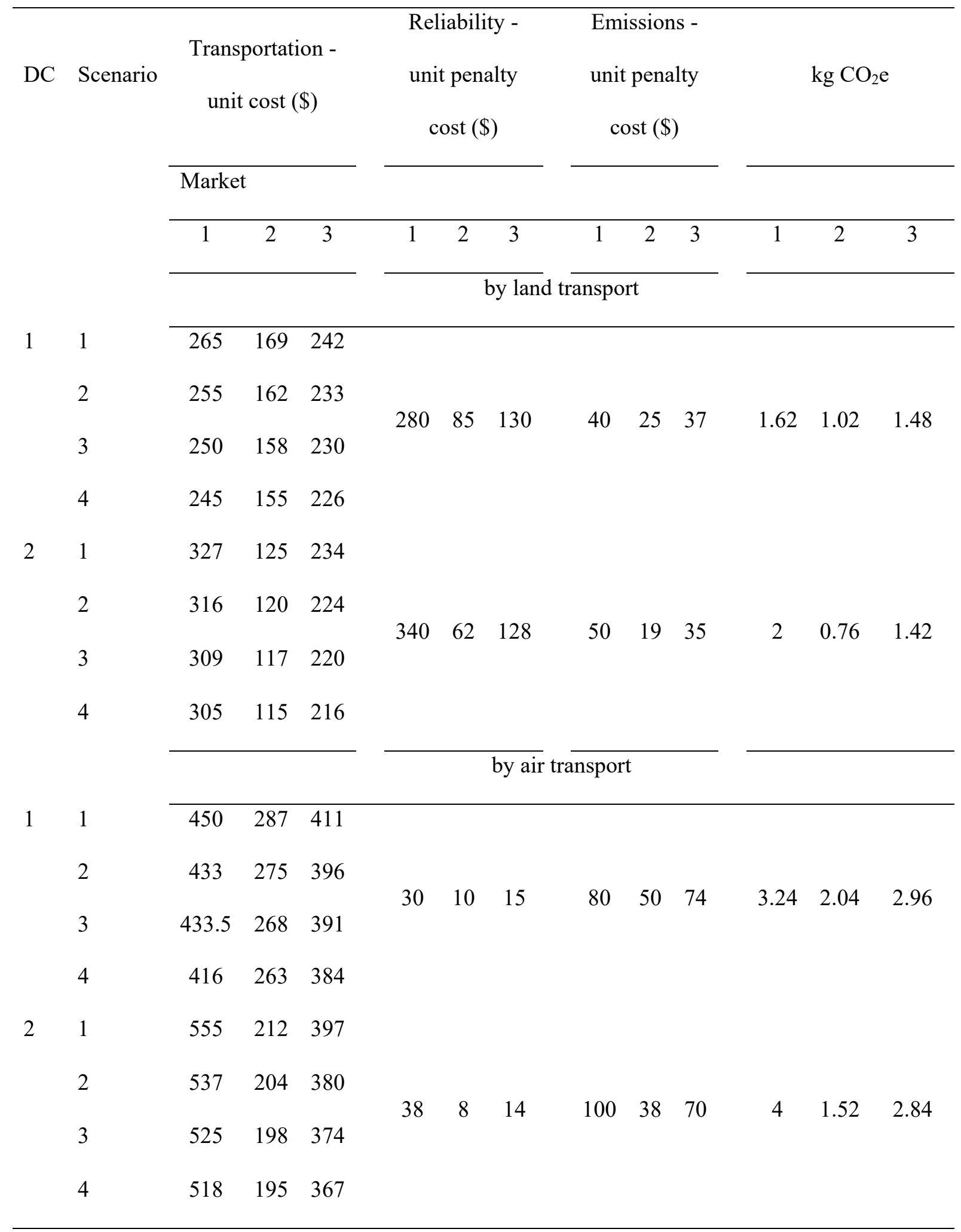




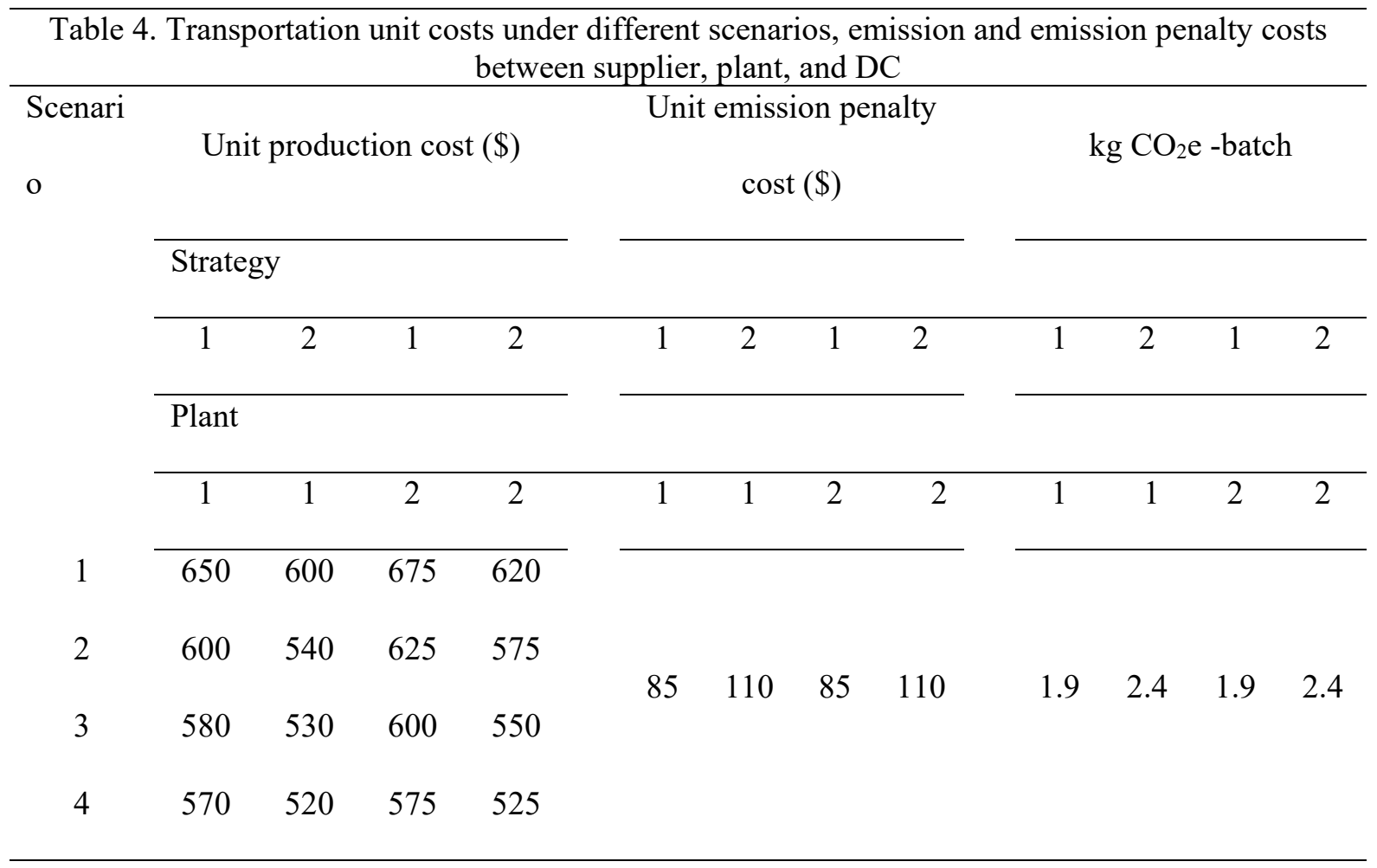

Table 5. Logistics performance indices and friction penalty costs under different scenarios

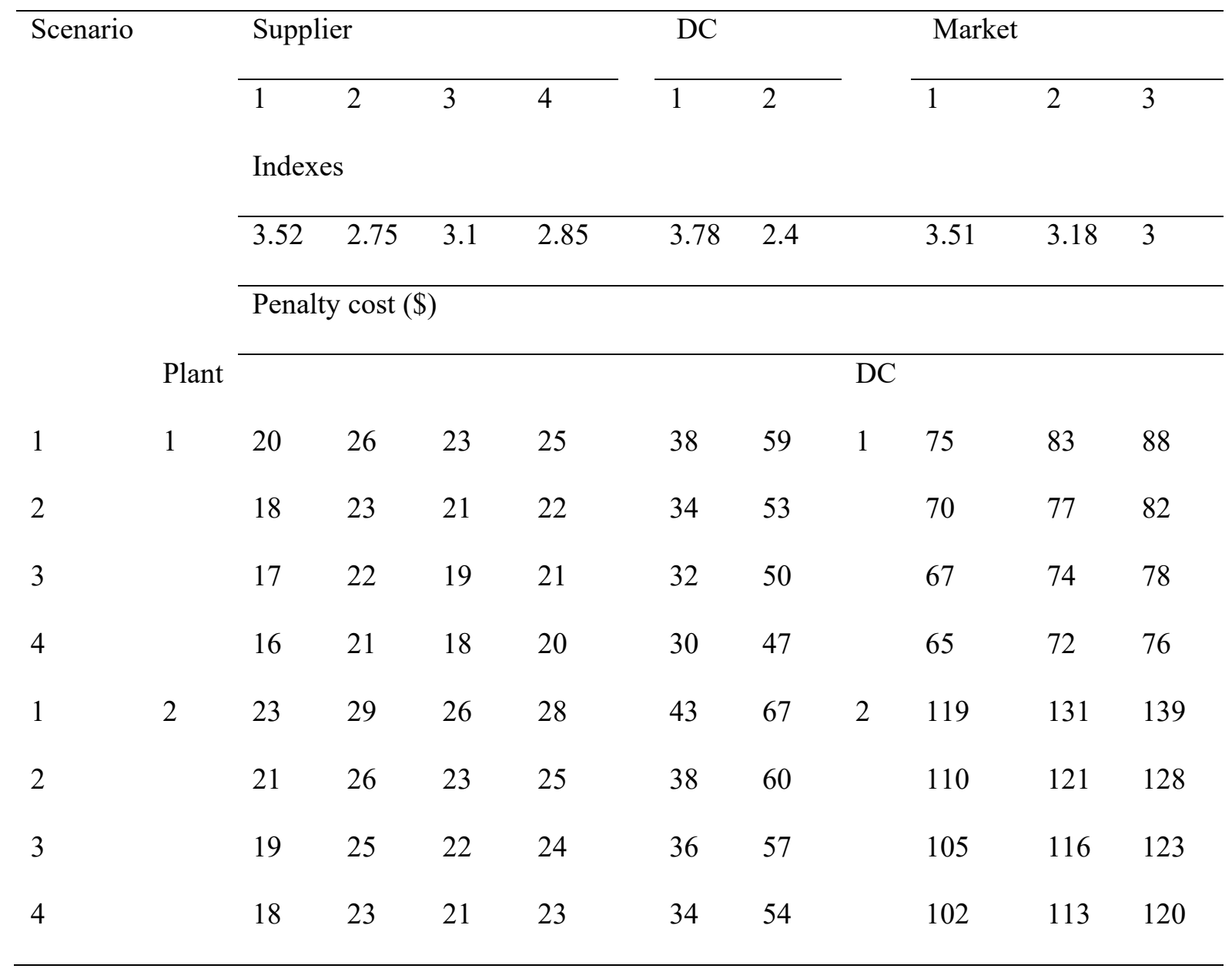


Table 6. Unit batch transportation costs under different scenarios, emissions, and emission penalty costs between DC and customers

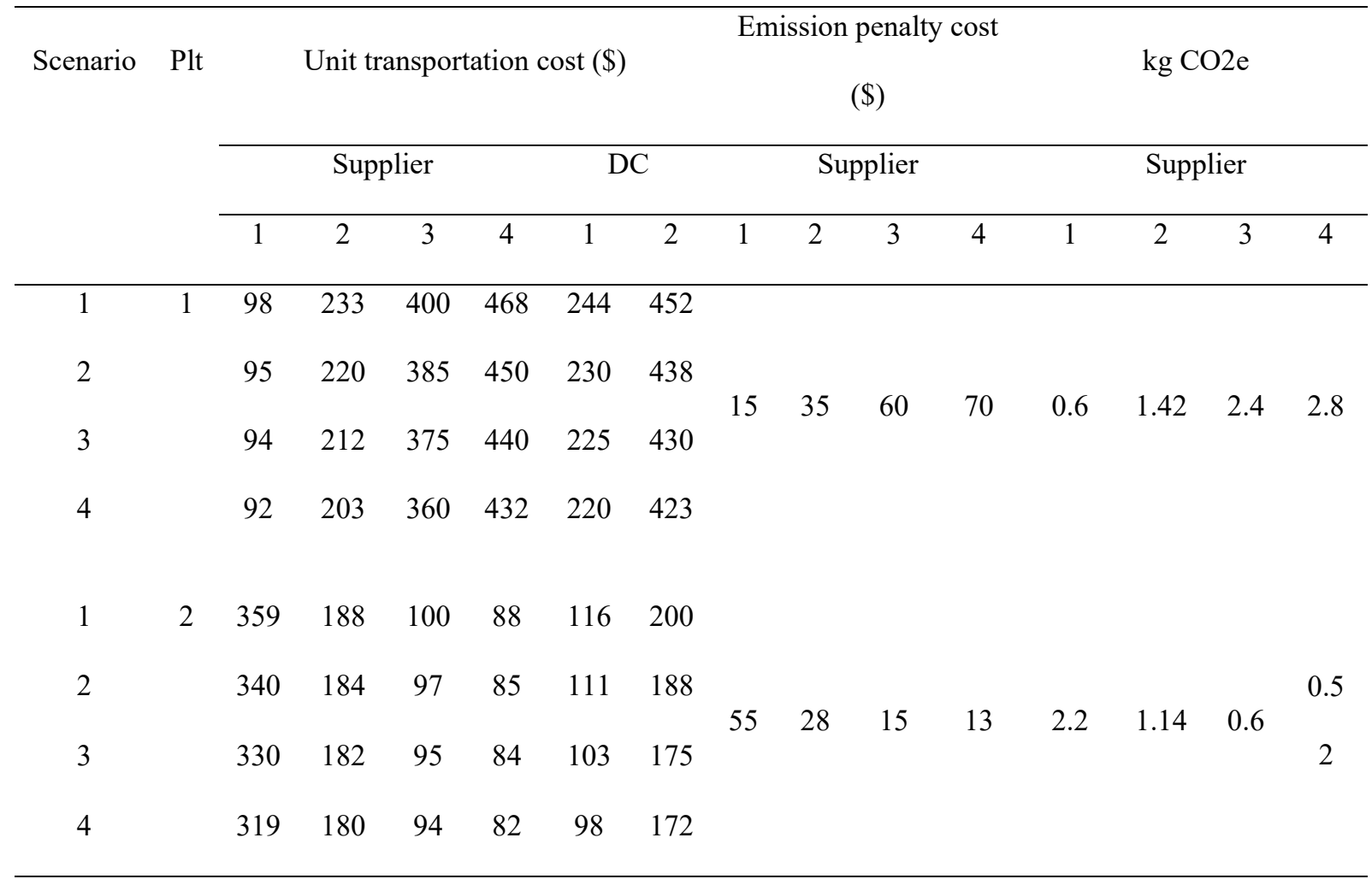




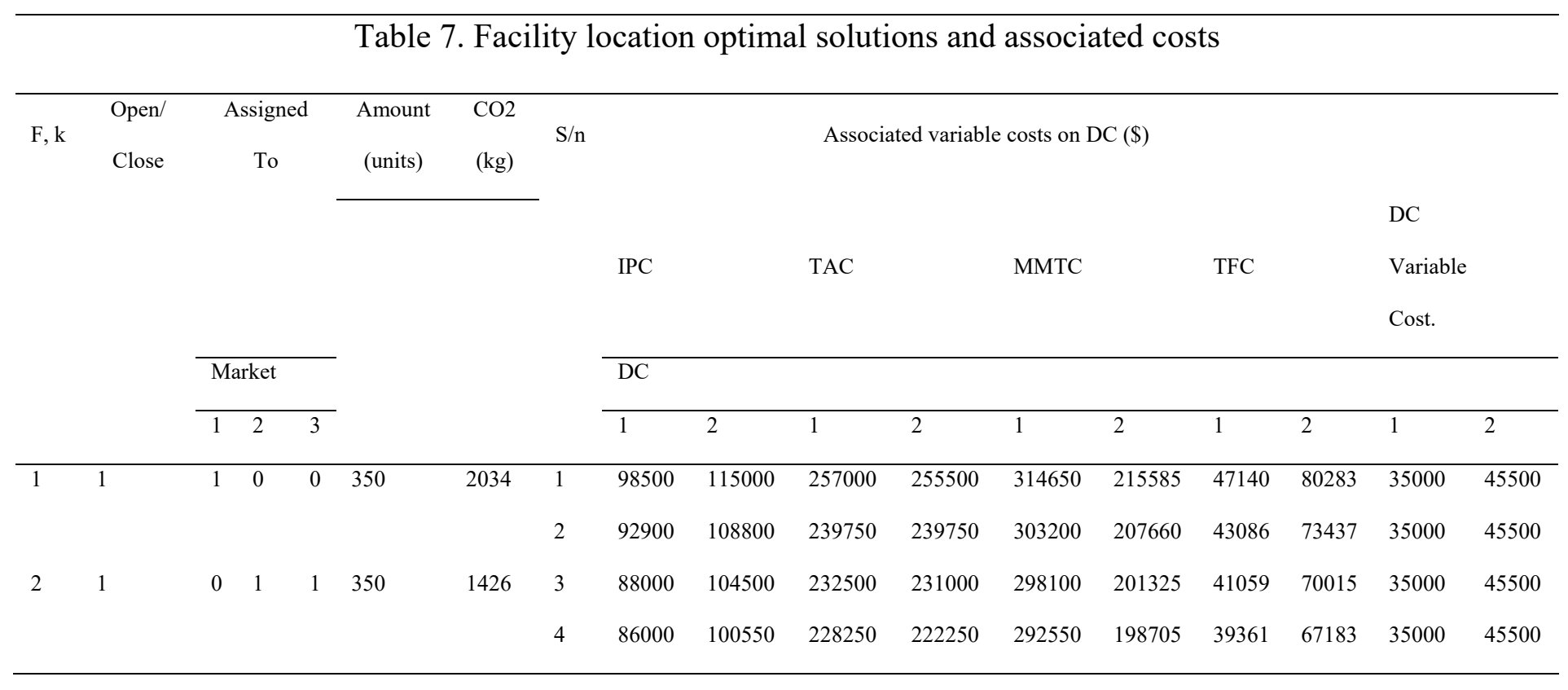


Table 8. Optimal production and shipment strategy

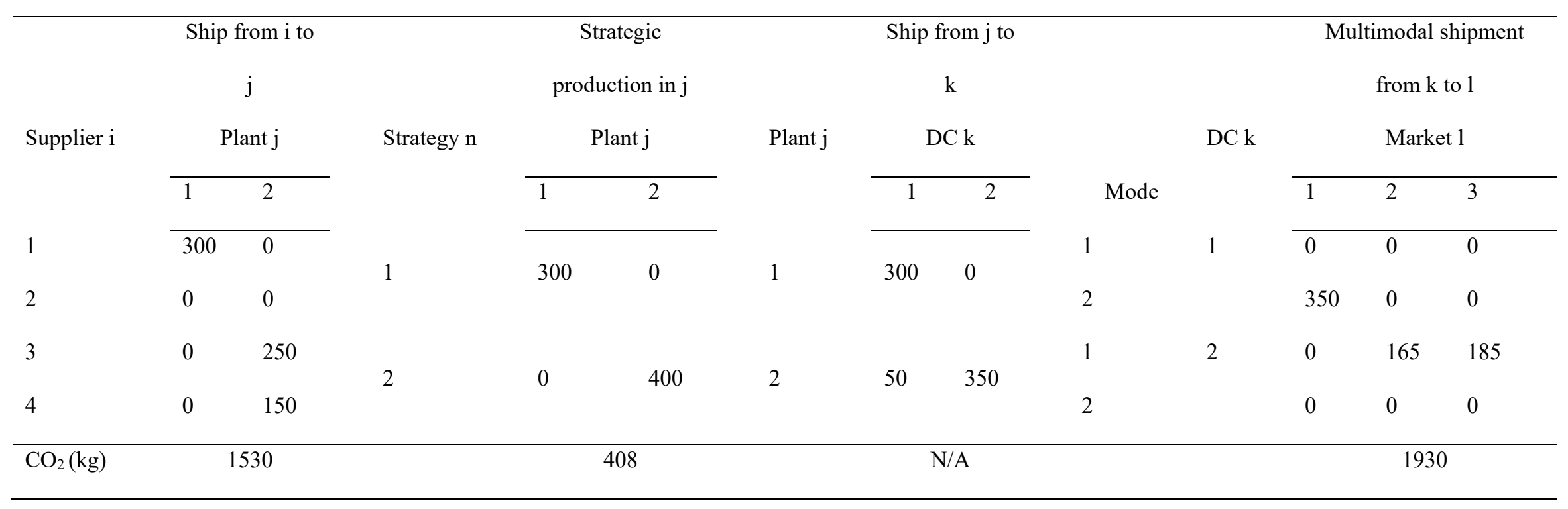


Table 9. Optimal total costs breakdown and over/under fulfillment

\begin{tabular}{|c|c|c|c|c|c|c|c|c|c|c|}
\hline \multirow[t]{3}{*}{$\mathrm{Sn}$} & Demand & & & \multicolumn{7}{|c|}{ Under-fulfillment/Over-fulfillment $\left(\mathrm{U}_{\mathrm{f}} / \mathrm{O}_{\mathrm{f}}\right)$} \\
\hline & \multicolumn{3}{|l|}{ Market } & \multicolumn{3}{|c|}{1} & \multicolumn{2}{|l|}{2} & \multicolumn{2}{|l|}{3} \\
\hline & 1 & 2 & 3 & & $\mathrm{U}_{\mathrm{f}}$ & $\mathrm{O}_{\mathrm{f}}$ & $\mathrm{U}_{\mathrm{f}}$ & $\mathrm{O}_{\mathrm{f}}$ & $\mathrm{U}_{\mathrm{f}}$ & $\mathrm{O}_{\mathrm{f}}$ \\
\hline 1 & 400 & 188 & 200 & & 50 & 0 & 23 & 0 & 15 & 0 \\
\hline 2 & 350 & 161 & 185 & & 0 & 0 & 0 & 4 & 0 & 0 \\
\hline 3 & 280 & 150 & 160 & & 0 & 70 & 0 & 15 & 0 & 25 \\
\hline 4 & 240 & 143 & 130 & & 0 & 110 & 0 & 22 & 0 & 55 \\
\hline \multicolumn{11}{|c|}{ Cost breakdown $(\$)$} \\
\hline & IPC & $\mathrm{TAC}$ & MMTC & $\mathrm{TFC}$ & $\mathrm{IHC}$ & $\begin{array}{l}\text { Fixed } \\
\text { (facility) }\end{array}$ & $\begin{array}{l}\text { Variable } \\
\text { (facility) }\end{array}$ & $\begin{array}{l}\text { Mean } \\
\text { var. } \\
\text { penalty }\end{array}$ & $\begin{array}{l}\text { Demand } \\
\text { var. } \\
\text { penalty }\end{array}$ & $\begin{array}{l}\text { Total } \\
\operatorname{cost}(\$)\end{array}$ \\
\hline 1 & 213500 & 512500 & 530235 & 127423.2 & 0 & 120000 & 80500 & 0 & 396000 & 1980158 \\
\hline 2 & 201700 & 479500 & 510860 & 116523.2 & 0 & 120000 & 80500 & 55070 & 0 & 1564153 \\
\hline 3 & 192500 & 463500 & 490675 & 108217.1 & 0 & 120000 & 80500 & 138810 & 0 & 1594202 \\
\hline 4 & 186550 & 450500 & 491255 & 106544.4 & 0 & 120000 & 80500 & 202150 & 0 & 1637499 \\
\hline
\end{tabular}


Table 10. Comparison between proposed robust and most probable deterministic solutions

\begin{tabular}{|l|l|l|l|l|l|l|}
\hline & \multicolumn{3}{|l|}{ Total cost under scenarios 1 to 4 (\$) } & Expected & RO expected \\
\hline & Sn1 & Sn2 & Sn3 & Sn4 & cost (\$) & cost saving (\$) \\
\hline D1 & 1796280 & 1715493 & 1693948 & 1660657 & 1741056 & 32583 \\
\hline D2 & 1991669 & 1494147 & 1475644 & 1446121 & 1708643 & 171 \\
\hline D3 & 2212815 & 1736623 & 1226562 & 1212427 & 1796053 & 87581 \\
\hline D4 & 2408558 & 1935387 & 1433302 & 1056457 & 1948699 & 240226 \\
\hline RO & 1981590 & 1502283 & 1483498 & 1453779 & 1708472 & - \\
\hline
\end{tabular}

Note: D1-D4 denote the four deterministic approaches.

List of Figures

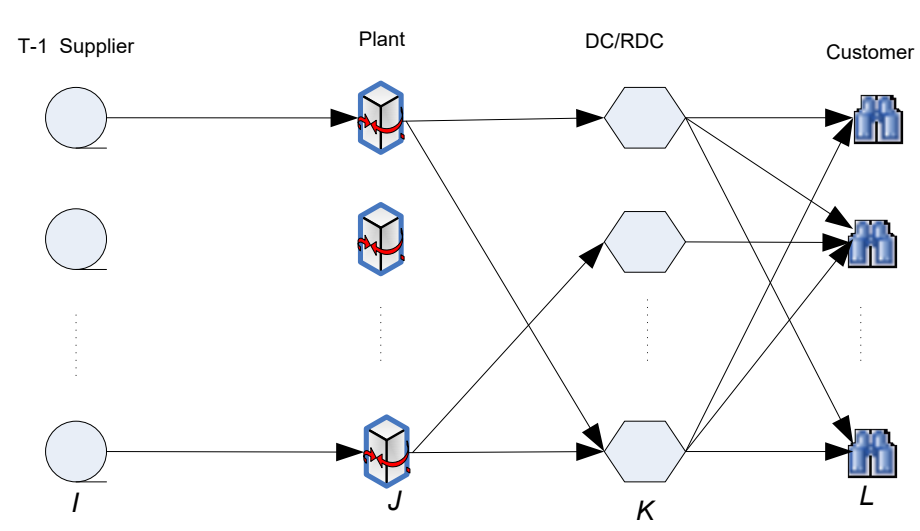

Figure 1. A typical 4-echelon global supply chain network 


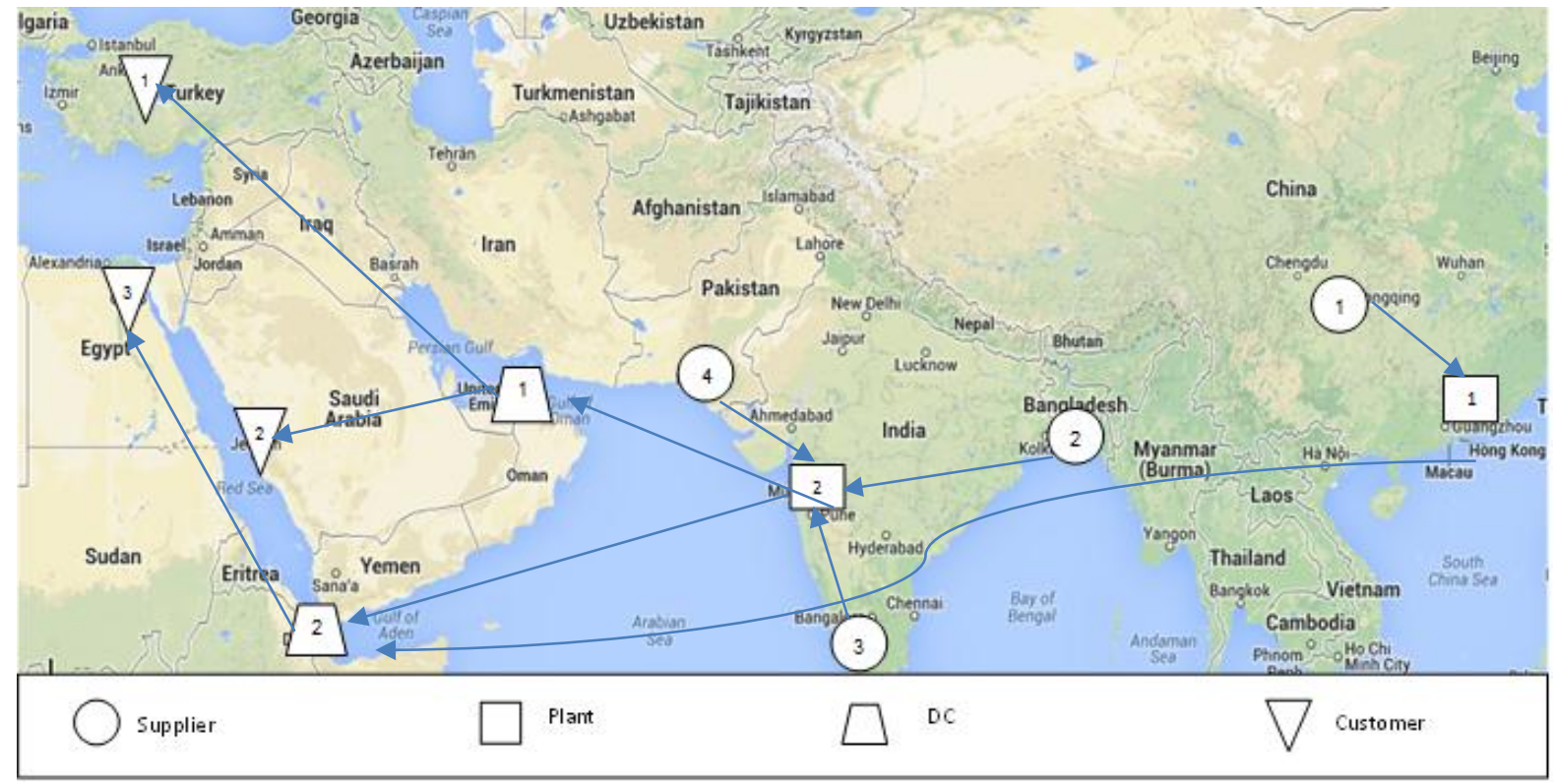

Figure.2. ABC global apparel supply chain network with possible DCs 


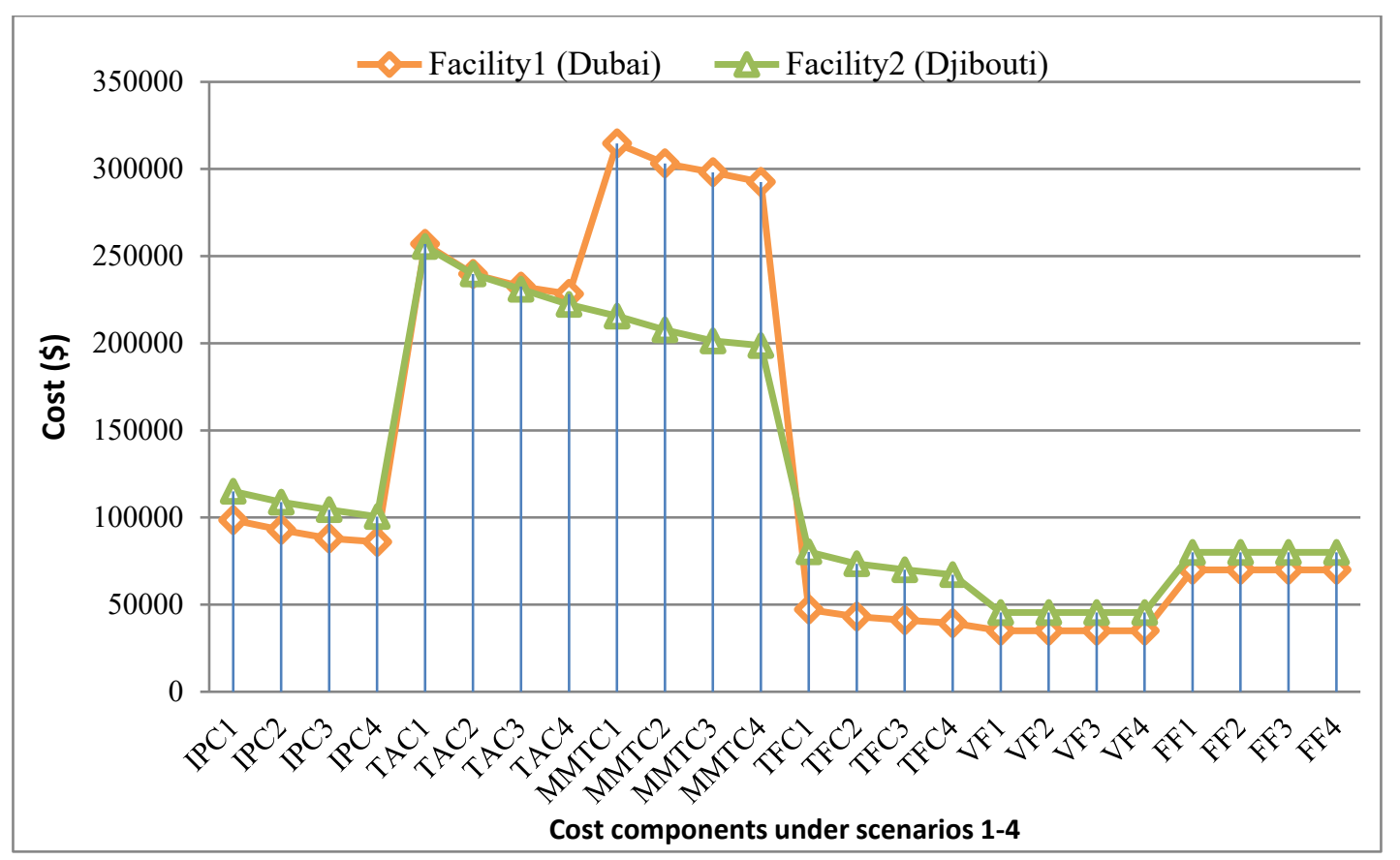

Figure 3. Optimal cost components for selected DC locations for scenarios 1 to 4

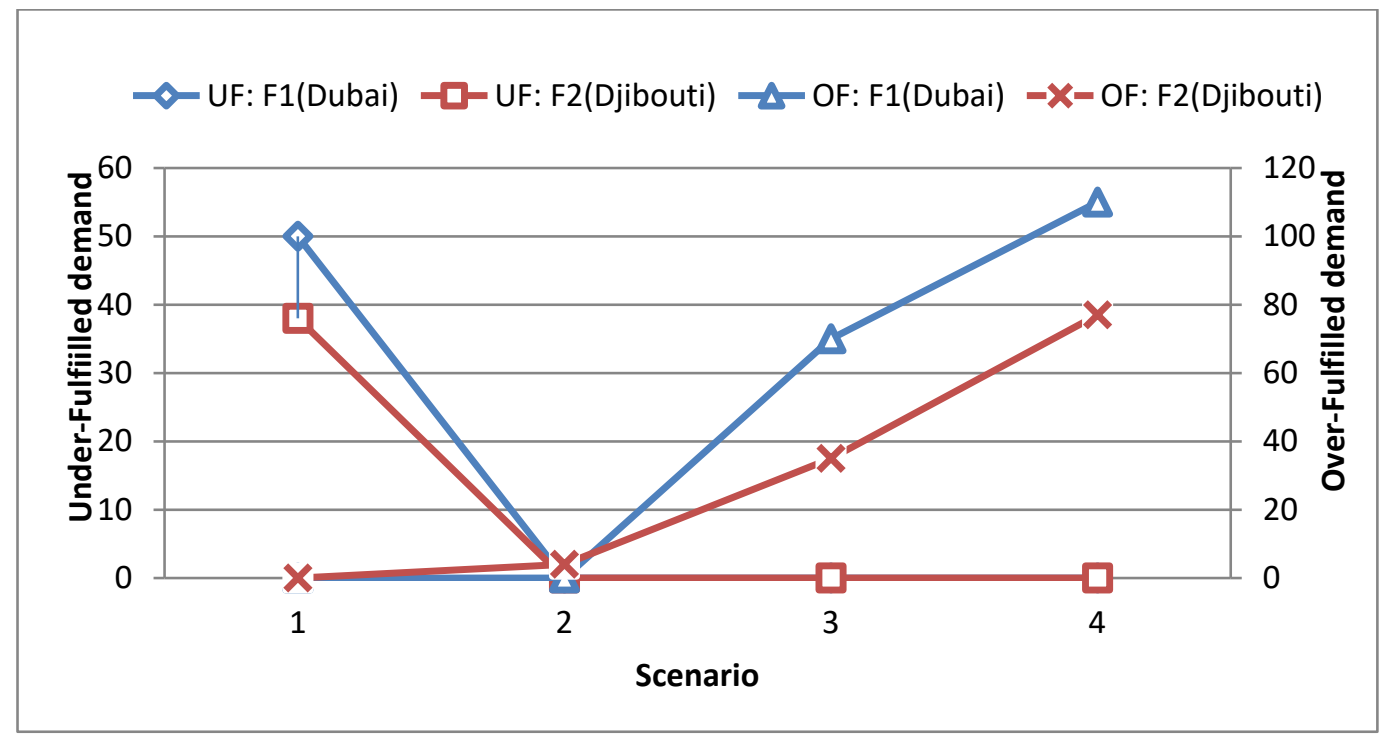

Figure 4. Optimal under/over-fulfillment in each market by selected DCs for scenarios 1 to 4 


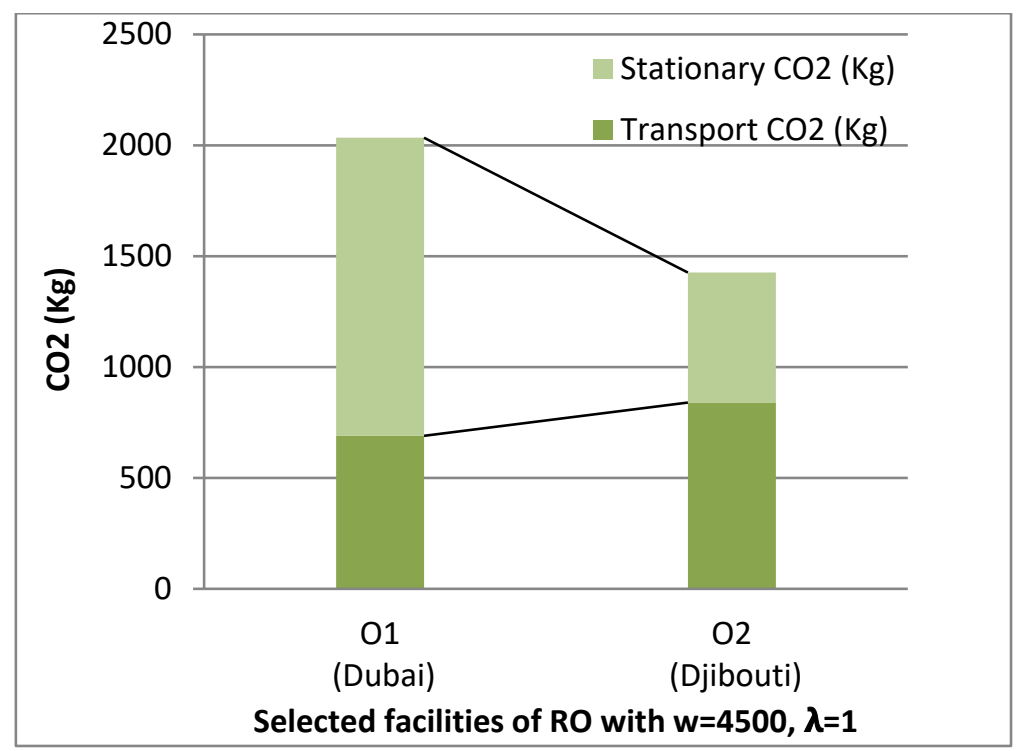

Figure 5. Transportation and stationary carbon emissions produced for each selected DC

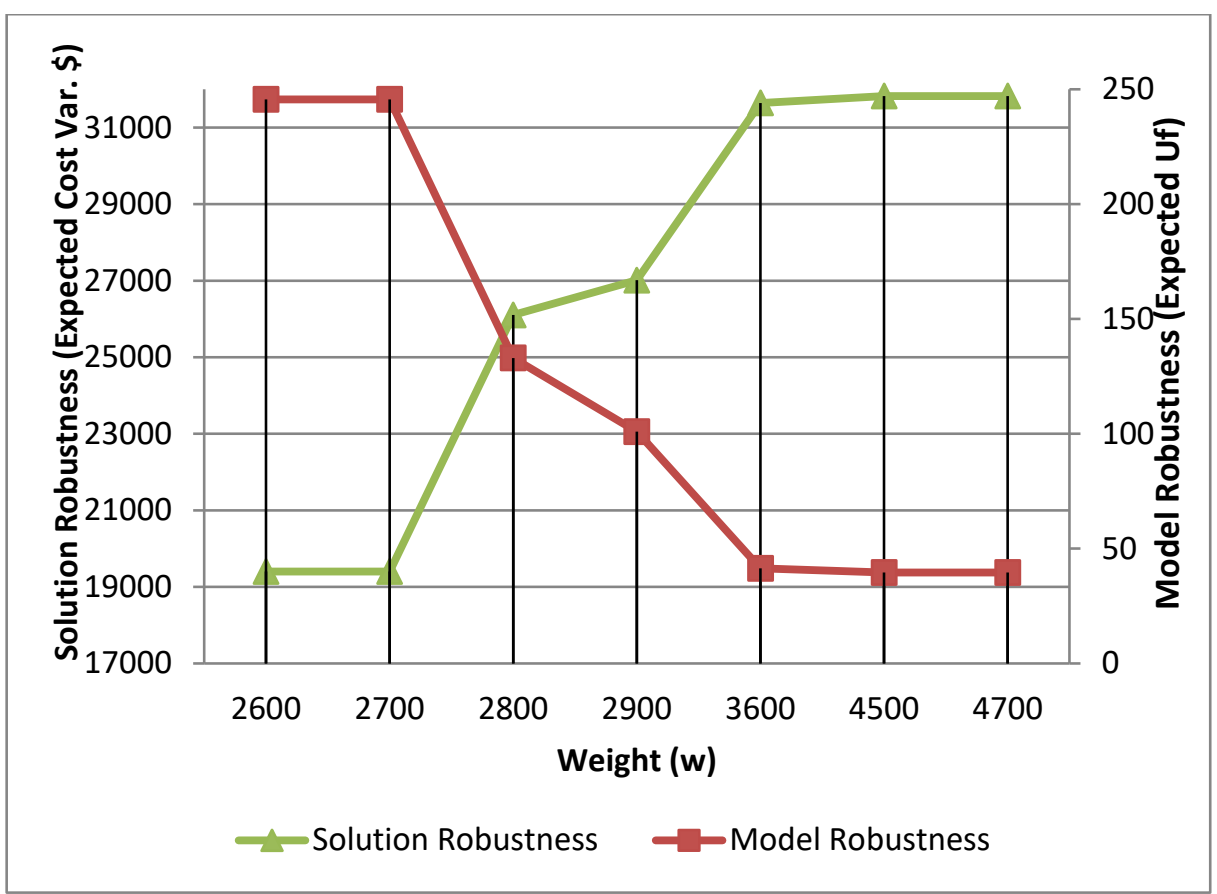

Figure 6. Trade-off between solution robustness and model 


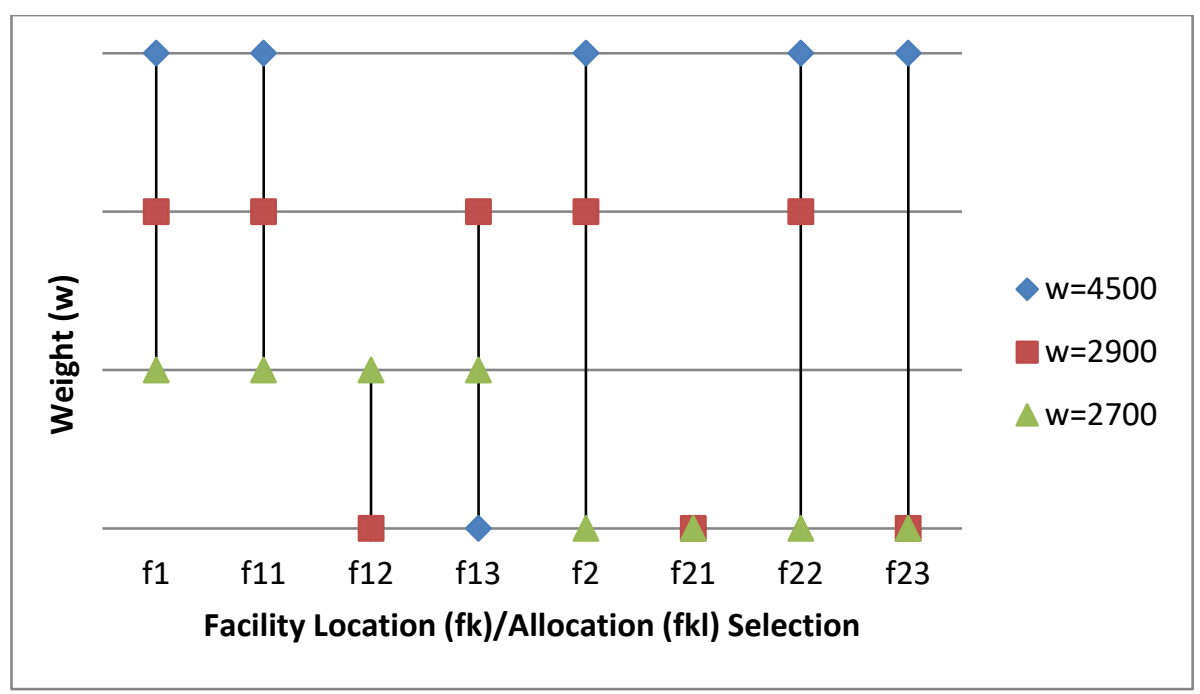

Figure 7. Sensitivity analysis of facility decisions to favored model robustness

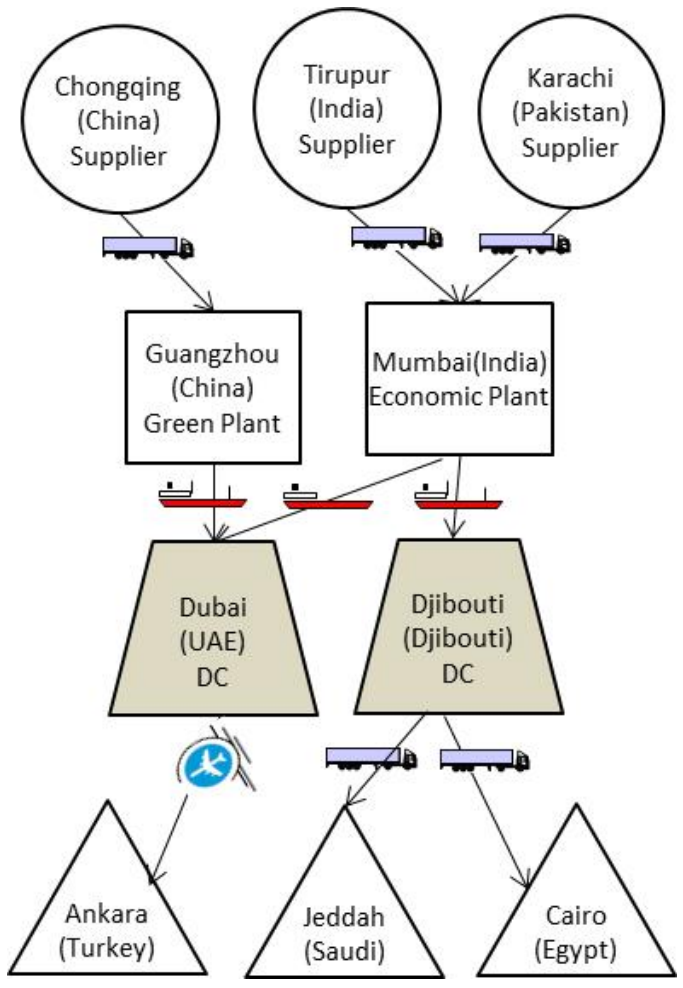

Figure 8. Design of optimized ABC global apparel supply chain network with selected DC's 


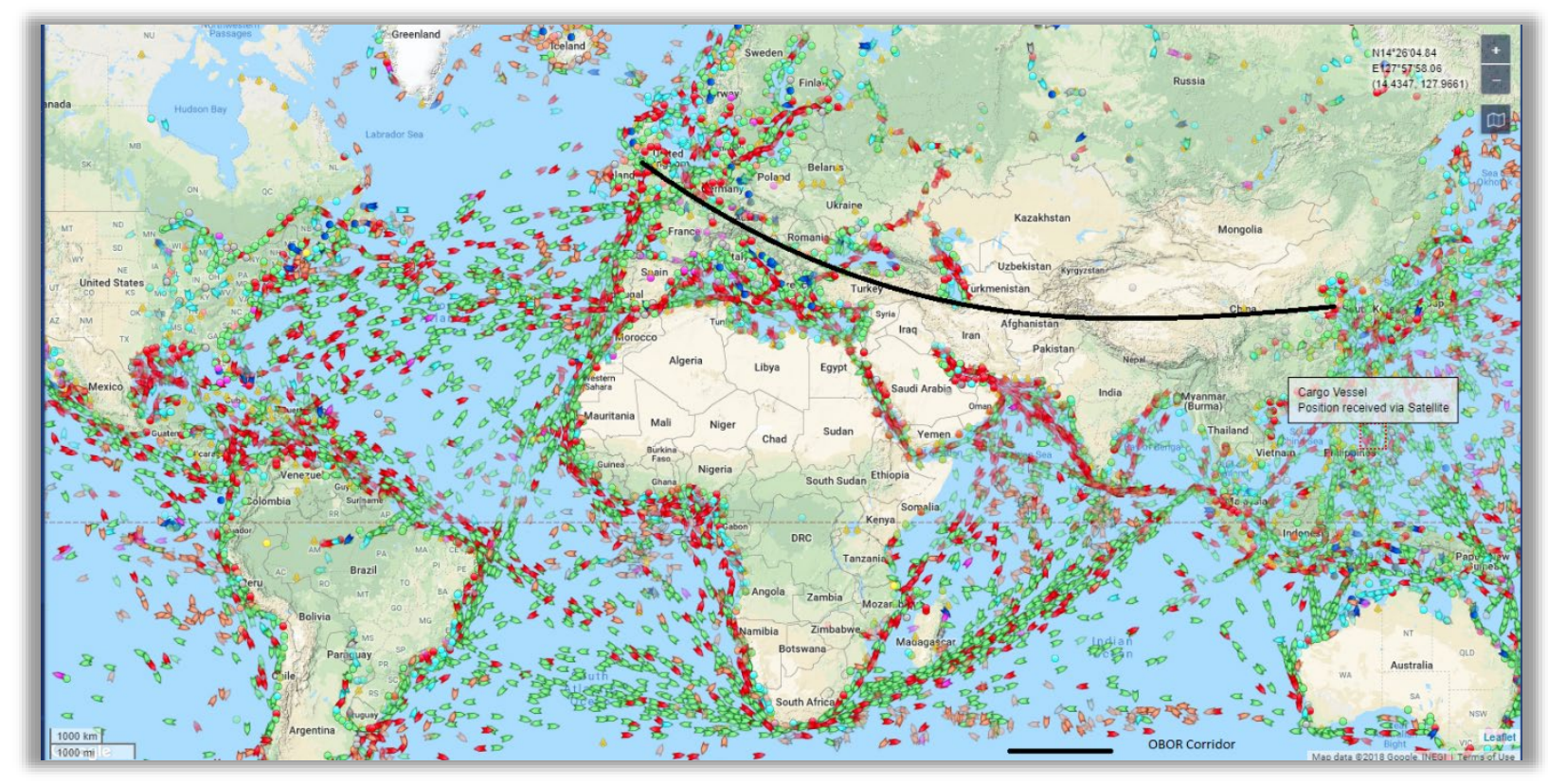

Figure 9. Proposed One Belt One Road (OBOR) corridor drawn by the author on a global live container traffic as on 18 June, 2019 (Source: Dubai Trade and Dubai Customs) 